JERR Y A. HA USMAN

Massachusetts Institute of Technology

\title{
Valuing the Effect of Regulation on New Services in Telecommunications
}

THIS PAPER DEALS with how to value the introduction of new services in telecommunications. Much public discussion has centered on the evolving "information superhighway" as well as on the many new services that may be offered as high-capacity fiber optic transmission networks are extended into the telecommunications infrastructure. The Federal Communications Commission (FCC) has decided to tax longdistance users to subsidize Internet access to schools and libraries. The cost is estimated to exceed $\$ 2$ billion a year. Numerous cable companies, such as Time Warner, have announced plans to upgrade their current coaxial-based networks to combined fiber-coax networks. This increased transmission capacity will allow many more channels of entertainment, high-speed access to information, and new interactive services.

How can society establish the value of these new services and increased choices? This question has potentially important economic consequences and equally important public policy implications. Because of the network structure of telecommunications, public policy has always played a large role in its production and regulation. In countries such as the United States and Canada, very strict regulation (which is only slowly being loosened) has limited the ability of companies to compete freely in telecommunications. By demonstrating how to value new telecommunications services, I allow for a more reasoned approach to the necessary benefit-cost calculations; this approach can help both 
to guide public investment in telecommunications infrastructure and to evaluate the effects of regulation.

To value new telecommunications services, I apply the method first introduced by the Nobel prizewinning economist Sir J. R. Hicks. ${ }^{1}$ The basic idea underlying the economic approach to valuing new goods or services is the recognition that until these goods actually come on the market, consumers are unable to purchase them at any price, no matter how much they would like to buy them. Thus, in some sense, the price of the new good or service might as well be infinite.

A more refined economic approach estimates the "virtual," or "reservation," price that sets demand for the new good or service to zero. At this virtual price, demand is zero, so a "virtual equilibrium" exists between demand and supply (which is zero). Estimation of the virtual price along with the expenditure function (demand curve) for the new good or service gives the economic value.

The actual price of the new service will usually be well below the virtual price. The quantity consumed multiplied by the difference between the virtual price and the market price (multiplied by one-half) approximates the fundamental gain in value, also called the consumer surplus, from the new service. ${ }^{2}$ This economic approach uses market demand to value new goods and services because the market establishes what consumers are willing to pay.

The introduction of new telecommunications services can lead to very large gains in consumer welfare. Consider voice messaging services introduced by local telephone companies in 1990; I estimate that the gain in consumer welfare from these new services was $\$ 1.27$ billion a year by 1994. Similarly, the introduction of cellular telephone services has led to estimated gains in consumer welfare of about $\$ 50$ billion a year.

Introduction of a new telecommunications service is typically much different from the introduction of a new good in an industry that is not regulated. If Kellogg or General Mills wants to introduce a new brand of cereal, it manufactures the cereal and convinces supermarkets to

1. Hicks (1940). I recently used this methodology to value new varieties of consumer goods; see Hausman (1996a).

2. This estimate is the calculation of the well-known welfare triangle, which measures consumer surplus and approximates the gain in consumer welfare. 
stock the new brand on their shelves. Consumers then decide whether the new brand will be successful by voting with their consumer expenditure. Regulation makes introduction of new telecommunications services much different. In the United States telecommunications companies must typically file an application with the FCC and state regulators. Potential competitors of the new service have economic incentives to attempt to stop or delay introduction of the new service. While regulators review the applications and attempt to sort out these claims, the new service can be delayed for many years, even decades. My approach allows estimation of the cost of these regulatory delays by valuing the economic gains that consumers would have had if the service had been available during the period of regulatory delay.

To assess the economic costs of regulatory delay, I first consider the particular example of voice messaging services offered by the Bell operating companies. AT\&T initially proposed to offer these services in the late 1970s. The FCC first delayed its decision and then refused to allow the Bell operating companies to offer these voice messaging services on an integrated basis with the rest of their telecommunications services. In 1986 the FCC reversed its decision. By then, however, the AT\&T divestiture decree, the Modification of Final Judgment (MFJ), forbade the Bell operating companies to offer voice messaging services. Two years later, in 1988, the MFJ court vacated the restriction on information services, which included voice messaging services, and the Bell operating companies began to offer the services the next year, more than ten years after they were first proposed to be offered. The services have been available since 1990, and about 16 million consumers bought them in 1996. If, as I estimate, the consumer value from these services was $\$ 1.27$ billion in 1994, then the approximate ten-year regulatory delay cost consumers billions of dollars. Applying the methodology to the cost of regulatory delay in the introduction of cellular telephone service, I estimate the cost to consumers to be closer to $\$ 100$ billion in total, with more than $\$ 25$ billion lost in a single year.

This cost of regulatory delay in the introduction of new telecommunications services has not received the attention it deserves. Although the potentially adverse effect of regulation on "dynamic economic efficiency" is often mentioned, the literature on the effects of regulation has largely ignored the actual effects of regulatory delays in 
new services. ${ }^{3}$ I calculate the loss in consumer surplus and also the effect on the telecommunications consumer price index from the introduction of these new services. Either alternative measure of consumer welfare demonstrates the significant consumer gains from the introduction of new telecommunications services and the very large cost imposed by regulatory delay in the introduction of these services.

Last, I consider the effect of current regulation on the future introduction of new telecommunications services. The FCC is aware of the cost of regulatory delay, which was widely discussed in the regulatory proceedings leading up to the FCC's decision to auction spectrum for personal communications services in 1994. In 1996, however, the FCC adopted new regulations to force local exchange companies to unbundle their networks and sell their services at very low prices to competitors. The pricing rules are being challenged in federal court, but if they are permitted to take effect, they will retard innovation and the future introduction of new services by telephone companies. Once again regulation will likely cost consumers billions of dollars.

\section{The Economic Valuation of New Goods}

Sir John Hicks made one of the first attempts to develop a theory for valuing new goods. In 1940 he valued social income and economic welfare using index number theory to analyze the effects of rationing and the introduction of new goods. Hicks correctly saw his approach as the basis for evaluating real income under these changes. Without completely working out the mathematics, he stated that for rationed goods the index numbers needed to be altered so that the price used in the index number calculated would lead to the amount of the ration being demanded. This higher price can be considered the "virtual price," which, when inserted into the demand function, leads to the observed amount of rationed demand ${ }^{4}$ For new products Hicks stated

3. See, for example, Joskow and Rose (1989) for a review of the effects of regulation. Oster and Quigley (1977) did find that regulation in the construction industry retarded diffusion of techniques, but they did not estimate the loss to consumer welfare from the regulation.

4. See Neary and Roberts (1980) for a modern treatment of rationing using this approach. 
that the virtual price for periods in which the goods did not exist would "just make the demands for these commodities (from the whole community) equal to zero.", 5

Modern economists recognize this price as the shadow, or reservation, price that is used in the demand function to set demand equal to zero. Of course, new products in a sense are a special case of rationing where the demand for the good is zero. Given the demand function, I can solve for the virtual price and for the expenditure function (or the indirect utility function) and correctly value social welfare without using the index number formulas discussed by Hicks. ${ }^{6}$

Rothbarth, in a 1941 paper on rationing, put the subject on firm mathematical footing and introduced the notion that a virtual price arises from the "price system with respect to which the quantities actually consumed are optimum . . . the "virtual price system. ${ }^{,{ }_{7}}$ I use his approach to demonstrate the effect on the price index, or real income, of the introduction of a new good. In period 1 consider the demand for the new good, $x_{n}$, as a function of all prices and income, $y$ :

$$
x_{n}=g\left(p_{1}, \ldots, p_{n-1}, p_{n}, y\right) \text {. }
$$

Now if the good were not available in period 0 , I solve for the virtual price, $p_{n}^{*}$, which causes the demand for the new good to be equal to zero:

$$
0=x_{n}=g\left(p_{1}, \ldots, p_{n-1}, p_{n}^{*}, y\right) .
$$

The index number approach, used by both Hicks and Rothbarth, then considers the change in real income to be the ratio $\left(p_{n}^{*}\right)\left(x_{n}\right) /\left(p_{n}\right)\left(x_{n}\right)$. Although this approach is approximately correct, it does not account for the need to change income $y$ as the price is increased in order to stay on the same indifference curve so that the marginal value of income does not change. Thus, instead of using the Marshallian demand curve in equations 1 and 2, I instead would use the income-compensated and utility-constant Hicksian demand curve to do an exact welfare evalua-

5. Hicks (1940, p. 144).

6. See Hausman $(1980,1981)$, who uses this approach in the context of female labor supply to make welfare calculations.

7. Rothbarth (1940-41, p. 100). 
tion. ${ }^{8}$ To find the (partial) expenditure function, I solve the differential equation from Roy's identity, which corresponds to the demand function in equation $1:^{9}$

$$
y=e\left(p_{1}, \ldots, p_{n-1}, p_{n}, u^{1}\right) .
$$

The expenditure function gives the minimum amount of income, $y$, to achieve the level of utility $u^{1}$ that arises from the indirect utility function, which corresponds to the demand function of equation 1 and the expenditure function of equation 3. To solve for the amount of income needed to achieve utility level $u^{1}$ in the absence of the new good, I use the expenditure function from equation 3 to calculate:

$$
y^{*}=e\left(p_{1}, \ldots, p_{n-1}, p_{n}^{*}, u^{1}\right) .
$$

The change in consumer welfare when the price decreases from the virtual price level, $p_{n}^{*}$, to the actual price level, $p_{n}$, keeping utility at the level $u^{1}$, is $y^{*}-y \cdot{ }^{10}$

Note that to use this approach, one must estimate a demand curve as in equation 1 , which in turn implies the expenditure function and the ability to do the exact welfare calculation of equations 3 and 4 . Thus,

8. In equation 3 , income, $y$, is solved out in terms of the utility level, $u^{1}$, to find the Hicksian demand curve given the Marshallian demand curve specification. Hausman (1981) demonstrates this solution procedure.

9. Hausman (1981) demonstrates how to solve the differential equation that arises from Roy's identity in the case of common parametric specifications of demand. Hausman and Newey (1995) demonstrate how to do the analysis when a nonparametric specification of demand is estimated.

10. It is sometimes asked whether consumers who buy the new product and discontinue their purchases of substitute products "lose consumer surplus" from not purchasing the older product, thus causing the consumer benefits from the new product to be overestimated. This calculation demonstrates that no "lost consumer surplus" arises so long as the older product continues to be available at its previous price. To the extent that other prices change, the changes in consumer welfare are incorporated straightforwardly into the welfare calculations because equations 3 and 4 are based on the expenditure function (for example, compensated demand curve) and are therefore path independent of price changes. Only when the older products disappear from the market do significant complications arise. Also, the analysis takes the representative consumer approach, which means it is not complicated by consumer switching from one product to another product because the representative consumer continues to purchase all products. Of course, one might prefer a discrete choice approach to the analysis if the data were available; see, for example, Berry, Levinsohn, and Pakes (1995). A discrete choice approach requires distributional assumptions on preferences, however, that may not be satisfied in the data. 
the only assumption required is to specify a parametric (or nonparametric) form of the demand function. Once the demand function has been specified and estimated, the expenditure function can be estimated and the standard errors calculated. ${ }^{11}$

\section{Estimation of the Demand Curve and Expenditure Function for Voice Messaging}

In 1996 demand for voice messaging services from local telephone companies in the United States exceeded 16 million subscribers. Local companies offer advanced voice mail features through their local central office switches. In addition to the usual voice mail features, other features include the ability to receive messages while the line is otherwise in use, partitioned mailboxes for various family members, and a broadcast facility to a group of numbers, which is useful for businesses, schools, and other organizations. Voice messaging, along with on-line information services, is one of the great success stories of enhanced telecommunications services offered in the past fifteen years.

To estimate the demand curve for voice messaging, I used aggregate state-level panel data from 1991 through 1994. Data on demand for BOC voice messaging was available over a four-year period, 1991-94, for eighteen states in the Midwest, Southwest, and West. ${ }^{12}$ The lefthand-side variable is the log of demand in units of subscription, while the primary right-hand-side variables, log of price and log of income, were deflated using the consumer price index. The price used is the state-specific price for the standard voice messaging service in each year. Prices vary in the sample from $\$ 2.80$ to $\$ 11$ a month. A log linear demand specification was used. Fixed effects for each state were included, as well as national and state-specific time trends, to allow for the price of substitute products, in particular telephone answering machines, and to allow for the differential growth in demand for voice

11. The expenditure function can be estimated using the techniques of Hausman (1981) or Vartia (1983) in the parametric case or of Hausman and Newey (1995) in the nonparametric demand function case. The standard errors are calculated using the techniques of Hausman (1981) and Hausman and Newey (1995).

12. Although I do not have price data on other states, penetration data (sales per telephone line) from other states are similar to my sample of eighteen states, so the results should be applicable to other states. 
messaging across states as more and more potential customers become aware of the service. The price of telephone answering machines decreased over the period, a phenomenon that the national time trends capture in the demand specification. ${ }^{13}$ Voice messaging was also introduced at different times, so each state could be at a different point along a diffusion curve, a factor that is captured by the state-specific time trends. Thus, the demand curve specification takes into account the price of substitute products as well as different diffusion rates in the different states.

To account for potential joint endogeneity of demand and price, I use the Hausman and Taylor approach of prices from different markets as instruments for prices in a given market. ${ }^{14}$ The approach assumes that the price in each state is determined to a significant extent by the cost of technology, which is determined in a national market. Because the states do not regulate the price for voice messaging, the price in each state is determined by this common cost of technology as well as by local demand conditions. Using a price index from other states (after removing state fixed effects) as an instrument for a given state removes state-specific effects while still capturing the cost element of voice messaging.

The results for a fixed effects specification estimated by both ordinary least squares (OLS) and instrumental variables (IV) are given in table 1 . The value of the demand elasticity for the IV estimate is greater (in magnitude) than that for the corresponding OLS estimate by about a factor of two. This increase in the demand elasticity is consistent with the use of an instrument that removes joint endogeneity of the price variable. The IV fixed effects specification fits quite well with the standard error, estimated to be $0.256 .{ }^{15}$ The estimated price elasticity is -1.61 , with an asymptotic standard error of 0.52 . Thus, the estimated (asymptotic) $t$-statistic is 3.09 , which indicates quite precise estimation. ${ }^{16}$

13. The price of a telephone answering machine is the same across different states except for different sales tax rates, which will be accounted for in the state fixed effects.

14. Hausman and Taylor (1981).

15. The $R^{2}$ measure for an OLS regression would be 0.999 , although this measure is not appropriate for an instrumental variable estimator.

16. A Hausman-type specification test would marginally reject the OLS estimates in favor of the IV estimates; see Hausman (1978). I use the IV estimates in the following consumer welfare calculations. 
Table 1. Voice Messaging Demand Estimates

\begin{tabular}{lcc}
\hline & \multicolumn{2}{c}{ Regression method } \\
\cline { 2 - 3 } Variable & $\begin{array}{c}\text { Ordinary } \\
\text { least squares }\end{array}$ & $\begin{array}{c}\text { Instrumental } \\
\text { variables }\end{array}$ \\
\hline Log of monthly price & -0.821 & -1.607 \\
Log of income & $(0.243)$ & $(0.523)$ \\
Log of population & 4.912 & 4.795 \\
& $(0.407)$ & $(0.423)$ \\
Intercept & 0.945 & 0.961 \\
& $(0.066)$ & $(0.068)$ \\
Number of observations & 6.790 & 7.343 \\
Standard error & $(0.541)$ & $(0.662)$ \\
$R^{2}$ & 61 & 61 \\
\hline
\end{tabular}

Source: Author's calculations.

Note: Standard error's in parentheses.

To estimate exact consumer welfare arising from a new telecommunications service, I also need to estimate the income elasticity. To do that, I use the estimated fixed effects for each state and a two-stage estimation approach (minimum chi square estimation). ${ }^{17}$ Here, average family income was used for each state in each year of the data. ${ }^{18}$ The results are given in table 1 . The estimates are $4.80(0.42)$ for income elasticity and $0.96(0.068)$ for population elasticity. The relatively high income elasticity is to be expected because voice messaging is likely to be a superior good, and the consumer welfare results are not particularly sensitive to the estimate, as I demonstrate subsequently.

Once the demand function for voice messaging is estimated, I turn to the expenditure function to estimate the value of voice messaging to

17. Minimum chi square (or minimum distance) estimation is similar to GLS (generalized least squares) estimation; see Malinvaud (1971) or Rothenberg (1973). I estimate the model in two steps to ensure that the price elasticity, which is the primary parameter needed for consumer welfare calculations, is consistently estimated. The use of a fixed estimator in the first stage guarantees consistency, given the correct specification. The second-stage estimate is similar to "between" estimation in panel data, but it attempts to correct for possible nonorthogonality of unobserved state-specific factors. See Hausman and Taylor (1981) for a further discussion. Other variables such as the ratio of business to residential access lines were included in the state-level specification, but they did not significantly affect the results.

18. Both households and small businesses purchase voice mail, so the family income variable can be interpreted partly as a disposable income measure as well. 
consumers. To estimate the overall effect on consumer welfare, I adopt an exact consumer surplus approach using the expenditure function for the log linear demand curve. I begin with the following expenditure function: ${ }^{19}$

$$
e(p, \bar{u})=\left\{(1-\delta)\left[\bar{u}+A p^{1+\alpha} /(1+\alpha)\right]\right\}^{1 /(1-\delta)},
$$

where $A$ is the intercept of the demand curve, $\alpha$ is the price elasticity, and $\delta$ is the income elasticity estimate. The compensating variation is calculated from equation 6 where $y$ is income:

$$
C V=\left[\frac{(1-\delta)}{(1+\alpha)} y^{-\delta}\left(p_{1} x_{1}-p_{0} x_{0}\right)+y^{(1-\delta)}\right]^{1 /(1-\delta)}-y
$$

For a new good, the expenditure function from equation 5 is used to calculate the compensated (Hicksian) demand curve, and the reservation, or virtual, price is calculated. ${ }^{20}$ This price can be used in the expenditure function of equation 5 to calculate consumer surplus from the introduction of the new good. Equation 6 has a straightforward interpretation in the case of a new good. The term $p_{0} x_{0}$ is the revenue spent on the new good in period 0 (before it is introduced). This term will be zero because $x_{0}=0$ so long as the product converges. ${ }^{21}$ For the simplest situation of no income effect, $\delta=0$, equation 6 reduces to expenditure on the new service divided by the price elasticity minus 1 . Thus, if a new good produces a large demand, $x_{1}$, the consumer surplus, or value to society of the new good, will be substantial.

To make the calculation corresponding to equation 6 and to area $\mathrm{A}$ in figure 1, I use the estimate of the voice messaging demand curve. The main parameter of the demand curve is the estimated price elasticity of $-1.61(0.52)$. Using the compensating variation formula from equation 6 , I estimate the consumer welfare from voice messaging services provided by the local exchange carriers to be $\$ 1.27$ billion. ${ }^{22}$ On aver-

19. Hausman (1981, eq. 3).

20. Hausman (1996a).

21. The price required to cause zero demand approaches infinity for the log linear demand function. The product, $p_{0} x_{0}$, converges to zero, however, if the price elasticity exceeds 1.0 .

22. The asymptotic standard error is 0.61 . The term denotes the estimated standard error based on the estimated asymptotic normal distribution. The distribution was adjusted for values of the price elasticity equal to -1.0 where equation 2 was not defined. 
Figure 1. Gain in Consumer Welfare from Introduction of a New Good

Price

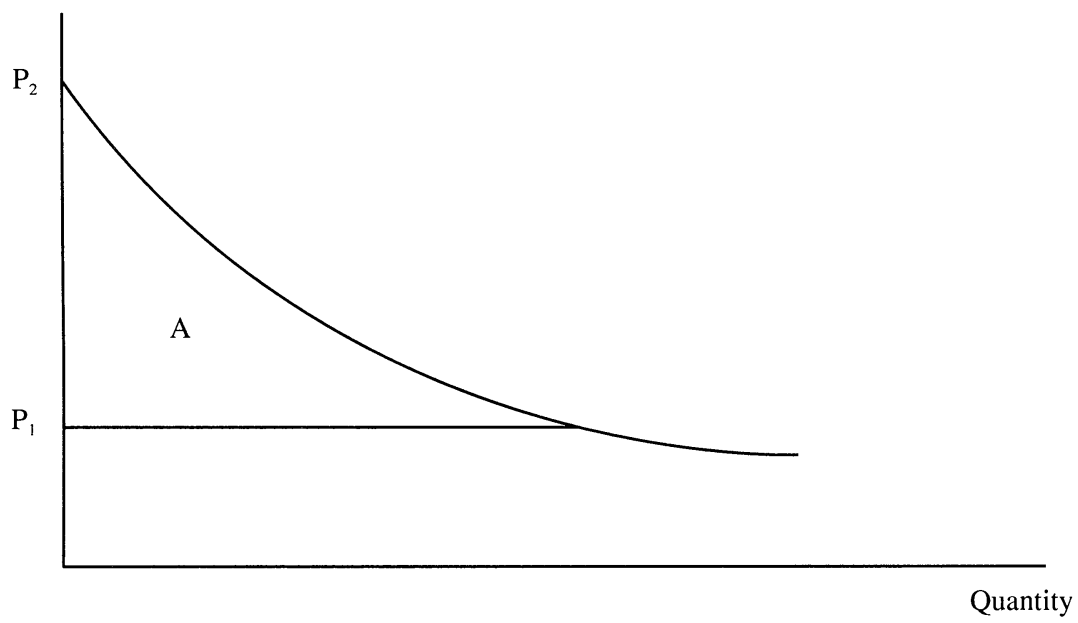

Source: Author's calculations. See text for explanation of terms.

age, each subscriber receives approximately the same amount in compensating variation as the subscriber pays for the voice messaging services. Note that the economic efficiency gain to the U.S. economy is even larger than $\$ 1.27$ billion because the calculation ignores the profit (producer surplus) from voice messaging services.

I now explore the range of results for the consumer welfare estimate. If the estimated income elasticity is replaced with a value of 1.5 , the gain in consumer welfare rises to $\$ 1.37$ billion; if the income elasticity is reduced to 0.5 , the estimated gain in consumer welfare is $\$ 1.40$ billion..$^{23}$ Thus, the results are not very sensitive to the estimated income elasticity.

A more serious concern may be the use of a log linear demand specification. Given the choice of a log linear demand curve, the virtual price, which sets demand to zero, approaches infinity. Thus, I use the following approximation as demonstrated in figure 2. I use the linear demand curve, which is tangent to the estimate demand curve at the mean of the data. The compensating variation estimated with this de-

23. The asymptotic standards of error are 0.57 and 0.56 , respectively. 
Figure 2. Linear Approximation to Consumer Welfare Gain

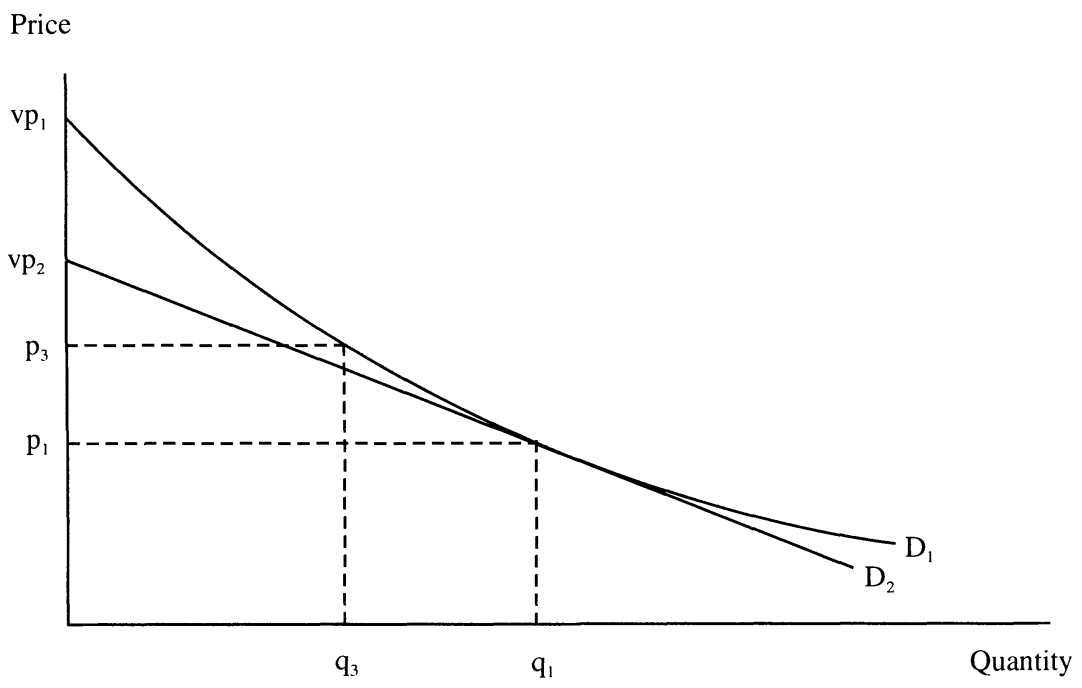

Source: Author's calculations. See text for explanation.

mand curve should be a lower bound estimate because the estimate at the mean of the data is always less than any other demand curve with the same elasticity unless the other demand curve is convex to the origin, which is counter to the usual intuition and experience with demand curves.

If a linear, rather than log linear, demand function is used, the estimate of consumer welfare from voice messaging would be about $\$ 480$ million a year. ${ }^{24}$ The estimated virtual price, at which there would be zero demand, is about $\$ 13$ a month. This is about $\$ 5$ higher than the actual population-weighted average price of $\$ 8$ in 1995. If anything, this virtual price estimate seems to be on the low side. For a small business (or residence) that uses voice messaging and does not want to lose calls, the savings from not having to purchase a second incoming line is about $\$ 25$ a month plus the cost of an answering machine (which

24. The asymptotic standard error is 156 . One could further consider variations in the estimates using the linear approximation because of uncertainty about the demand elasticity parameter. For instance, a 95 percent confidence interval would go from about $\$ 235$ million up to $\$ 1.1$ billion. The resulting compensating variations estimates remain quite significant. 
would be small). Using this value as the virtual price in the log linear demand specification leads to an estimate of consumer welfare of about $\$ 2.1$ billion a year, which is above the log linear compensating variation estimate. ${ }^{25}$

Thus, I find that the range of the compensating variation estimates, about $\$ 480$ million to $\$ 2.1$ billion, is most likely centered around the log linear demand curve estimate of about $\$ 1.2$ billion. Clearly, new telecommunications services can create significant value for consumers, and government actions that either speed up or delay the introduction of these new services can affect the economic welfare of its citizens substantially.

\section{Regulatory Delay and the Introduction of Voice Messaging}

Voice messaging using central office-based telephone technology was sufficiently developed to begin operation in the early $1980 \mathrm{~s}^{26}$ AT\&T applied to the FCC in 1981 for permission to provide "Custom Calling II" services, which included voice messaging services, on an unseparated basis, that is, these services would have been integrated with basic local exchange service. The FCC rejected AT\&T's request. ${ }^{27}$ AT\&T stated that a redesigned system for structural separation would take three years to introduce, and the additional costs would be substantial. Because it was "technically possible"' to provide structurally separated voice messaging, the FCC decided to bar AT\&T from providing it on an integrated basis. The additional economic costs that AT\&T said it would incur if it were forced to separate the two kinds of service played only a minor role in the FCC decision.

A few months later, the court judgment divesting AT\&T of the Bell operating companies prohibited those companies from providing "in-

25. The asymptotic standard error is 0.37 .

26. See Rey (1983) for an early description of the development of AT\&T's custom calling services.

27. AT\&T Petition for Waiver of Section 64.702 of the Commission's Rules and Regulations 118,88 F.C.C. 2d 1 (1981). AT\&T had claimed that it would need to redesign its network equipment to provide voice messaging on a structurally separated basis. Rejecting the claim, the FCC recognized the presence of economies of scope in voice messaging ( $\$ 17)$ but feared a "slippery slope" regarding possible cross-subsidies that would create regulatory uncertainty. 
formation services,' which included voice messaging. The combined effect of the FCC decision and the court judgment was to preclude the Bell operating companies from offering voice messaging to small business and residential customers. Despite the FCC's stated belief that competing service providers would offer voice messaging, they never did so. Thus, residential and small business customers did not have the opportunity to purchase voice messaging services.

In March 1988 the judgment was modified to permit the Bell operating companies to transmit information services (although they were still prohibited from providing content for those services). ${ }^{28}$ In 1988 the FCC also began approving comparably efficient interconnection plans that allowed the operating companies to provide individual enhanced services, such as voice messaging, on a structurally integrated basis. These regulatory changes permitted the operating companies to offer the voice messaging services they had originally petitioned to provide in 1981. In practice, they introduced voice messaging services in 1990, five to seven years later than they would have been introduced had it not been for the FCC and the court delays. How much did that delay cost consumers?

For the initial case of similar demand and price in 1988 as 1994, I estimate the lost consumer welfare to be $\$ 1.27$ billion (in 1994 dollars). This calculation is based on the demand curve for voice messaging estimated above as well as on the formula for compensating variation in equation 6.

Suppose that the FCC had not delayed, but instead had allowed the operating companies to provide voice messaging services starting in 1984 on an integrated basis. For illustrative purposes, suppose that technology had not been as advanced or that competition from other forms of voice messaging equipment, such as answering machines, had been less. ${ }^{29}$ Assume, as a result, that price would have been 50 percent higher with a corresponding decrease in quantity demanded. Consumer welfare would decrease by about $\$ 170$ million. The regulatory delay

28. Opinion of Judge Harold Greene on the First Triennial Review, September 10, 1987, Section V.

29. Indeed, in the early 1980s the technology would have been based on a mainframe computer system, whereas the technology is now based on personal computers. Thus, the price could have been 50 percent higher in the earlier period. 
Table 2. Estimated Lost Consumer Welfare in 1988 because of Voice Messaging Delay (1994 Dollars)

\begin{tabular}{lccc}
\hline Scenario & Penetration & Assumed price & Lost welfare \\
\hline Similar to 1994 & 1994 level & 1994 price & $\$ 1.27$ billion \\
Higher price & 1994 level & $50 \%$ higher & $\$ 1.0$ billion \\
\hline
\end{tabular}

Soruce: Author's calculations.

still would have cost consumers $\$ 1.10$ billion in lost welfare in 1988 (table 2).

These calculations demonstrate a very important result in economic analysis. Consumer welfare gains from the introduction of a successful new product are usually quite large. In the theory of international trade such gains explain why a tariff is superior to a quota. ${ }^{30}$ In public finance theory these gains explain why, in times of shortage, tradable ration tickets are superior to a nontradable framework. The gain in consumer welfare here is even larger because when regulation holds up the introduction of a new good or service, it is equivalent to a quota or a ration having a zero value.

Why, then, would regulators impose such a large loss on U.S. consumers? The FCC's stated concern was that a cross-subsidy from the local exchange service might occur if AT\&T were permitted to provide voice messaging services on an unseparated basis. Although this concern had some merit given the use of rate of return regulation at the time, regulators never made the fundamental calculation of comparing lost consumer surplus from not permitting introduction of voice messaging with the possible consumer harm from some amount of crosssubsidy. ${ }^{31}$ No rational calculation about consumer benefit was ever made. A "public interest" consumer welfare standard seems far from the FCC's actual decision process, although such a standard is supposed to guide FCC decisions.

30. See Romer (1994) for a theoretical discussion of welfare costs from trade restrictions.

31. A discussant of my paper, Dr. Greg Rosston, who recently served as an economist at the FCC, stated that the commission may have used permission to offer voice messaging as a "bargaining tool" or "pawn in the game"' to attempt to force AT\&T to open its network to competitors. This quite revealing remark fails to recognize that consumers are the ultimate pawns in the regulatory game, because it is consumer welfare that is reduced when the FCC delays the introduction of new services in an attempt to achieve other regulatory goals. 
Figure 3. Number of Cellular Subscribers: 1985-96

Millions

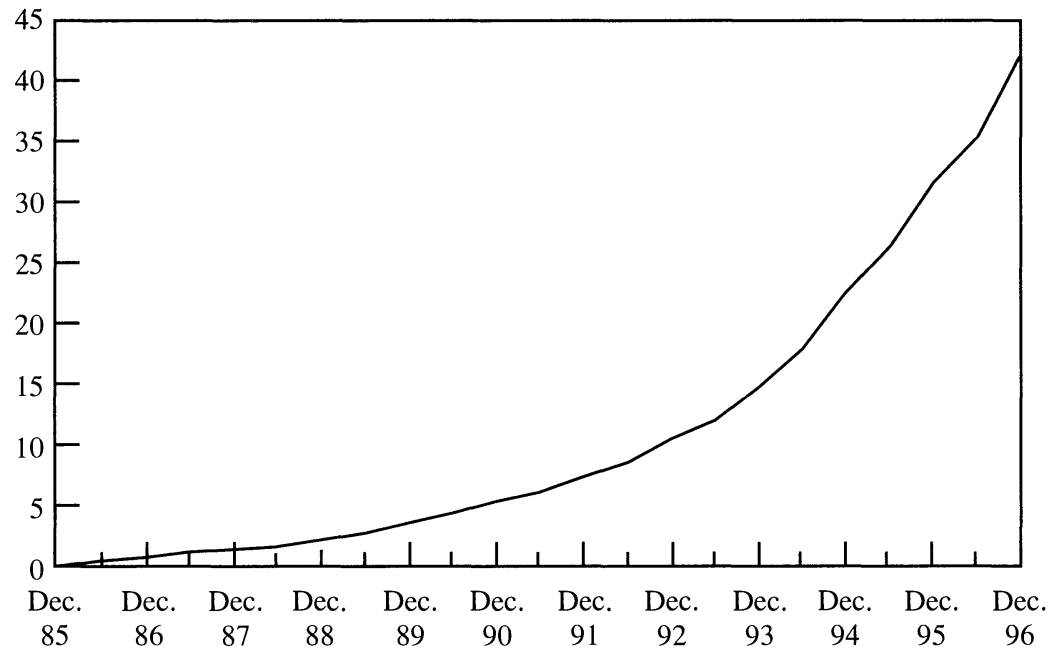

Source: Cellular Telephone Industry Association.

The situation worsened considerably once the federal court became involved in working out the plan to break up AT\&T; until the Supreme Court required otherwise in 1994, the federal court judge followed a legalistic approach to regulation rather than one that explicitly considered consumer welfare or the public interest.

\section{The Effect of Regulatory Delay on the Introduction of Cellular Telephone}

Cellular telephones are an example of a new product that has significantly affected how Americans live. Since cell phones were introduced in the United States in 1983, demand has increased 25-35 percent a year (figure 3). By the end of 1996, about 42 million cell phones were in use-about one-third the number of regular (landline) telephones. About 16 percent of all Americans used cellular telephones.

Cellular telephones were introduced first in Chicago in late 1983 and then in Los Angeles during the 1984 Olympic Games. Within the next 
year operations began in the other top thirty metropolitan statistical areas (MSAs) and subsequently spread to the rest of the country. Cellular telephone service is now available almost everywhere within the United States.

Cellular telephone has been, along with 800 telephone service, the great success story of new telecommunications services offered in the past forty years. At the time of the AT\&T divestiture when it was not clear whether AT\&T or the divested Bell operating companies would inherit the cellular spectrum that the FCC had granted to AT\&T, an AT\&T prediction for cellular subscription levels in the year 1999 was about 1 million. By the end of 1996 cellular subscribership had already reached 42 million (figure 3). ${ }^{32}$ In 1996 the next generation of cellular technology, PCS, was introduced in the United States, so growth rates for mobile telephone usage were likely to continue at their high levels, or even increase, during the next few years.

The average cellular subscriber spends $\$ 48.84$ a month on cellular service, or just under $\$ 600$ a year; altogether about $\$ 24$ billion a year is spent on cellular service, with additional amounts spent by consumers on purchasing cellular telephones. Revenue from cellular service in 1996 was about one-third as large as revenue from long-distance service, so cellular telephone represents a significant expenditure category in telecommunications (figure 4).

\section{Cause of Regulatory Delay in the Introduction of Cellular Telephone}

Cellular telephone technology was sufficiently developed to begin operation in the early 1970s. In practice, however, cellular service did not begin in the United States until 1983. ${ }^{33}$ The delay in providing cellular telephone was caused by regulatory indecision and the subsequent licensing procedure used by the $\mathrm{FCC}$, which was in charge of the cellular spectrum. The FCC could not decide whether to give AT\&T an exclusive right to provide cellular service, to give that right to nonAT\&T companies such as paging companies, or to allow competition

32. These data are from the Cellular Telephone Industry Association (CTIA), Washington, D.C.

33. See Lee (1982) and Calhoun (1988) for histories of the development of cellular telephone. The FCC began its inquiry to reallocate additional spectrum for mobile telephone service in 1968. 
Figure 4. Cellular Service Expenditures as a Percentage of Long-Distance Expenditures: 1987-96

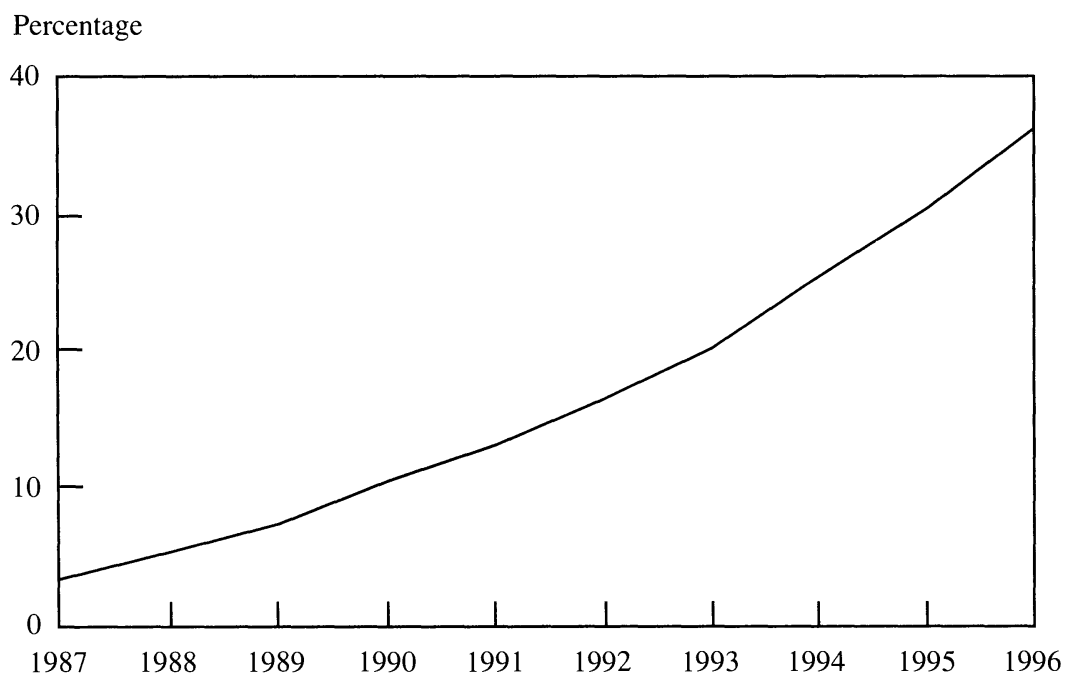

Source: Cellular Telephone Industry Association, Federal Communications Commission.

between the two groups. AT\&T had invented cellular and argued that only one provider should be present in each MSA because of significant economies of scale in spectrum usage. Potential entrants into cellular service argued that AT\&T should be barred from the market because cellular telephones could compete with AT\&T's landline local monopoly at some time in the future. This delay led to extremely large losses in consumer welfare.

Initially the FCC made one decision and then another. Finally, in the early 1980s it decided to allow two cellular providers in each MSA. This duopoly situation was a departure for the commission, which previously had not allowed competition (although competition did exist in the provision of "Improved Mobile Telephone Service," the car telephone service that preceded cellular service). Interestingly, most other nations followed the U.S. lead in initially allowing for two cellular companies. The FCC decided to award 20 megahertz $(\mathrm{MHz})$ of spectrum to each of the two cellular providers, with $10 \mathrm{MHz}$ of spectrum kept in reserve. In 1986 the FCC awarded $5 \mathrm{MHz}$ of additional spectrum 
to each of the two cellular providers so that each had $25 \mathrm{MHz}$ of spectrum. ${ }^{34}$

The FCC awarded the B block, or "wireline," cellular frequency to the wireline telephone company in each MSA. Of course, this company was usually a Bell operating company except for areas where GTE or an independent telephone company was awarded the spectrum. In several MSAs two or more wireline companies formed a partnership to operate the so-called wireline network. ${ }^{35}$ To award the A block, or nonwireline, cellular frequency, the FCC originally decided to conduct "comparative hearings" to decide who proposed the best cellular network. This procedure soon threatened to create a morass of evidentiary and legal wrangling, so the FCC encouraged contenders to form partnerships. Companies such as Communications Industries, MCI, Metromedia, the Washington Post, and LIN Broadcasting became partnership members and were awarded these nonwireline franchises.

Because of procedural delays in awarding the nonwireline franchises, the wireline networks typically began operation a year or two earlier than the nonwireline networks. The exceptions were Boston and Washington, where regulators delayed operation of the wireline network until the nonwireline network could begin operation. The headstart given the wireline networks elsewhere had no adverse effect on subsequent competition, however, and consumers had the advantage of earlier use of cellular telephones. Because the nonwireline networks were able to resell the wireline carrier's service until they began operation, most consumers did not realize that they were using the wireline network. By 1996 the nonwireline carrier in numerous MSAs had significantly surpassed the wireline carrier in subscribers, notwithstanding their delayed beginning of operations, by offering innovative service packages better suited to customer demands.

After realizing the problems of comparative hearings, the FCC sub-

34. The relatively small amount of spectrum awarded for cellular service in the United States led to severe capacity problems in MSAs such as Los Angeles and New York in the late 1980s and early 1990s. The demand for cellular was considerably greater than any forecasts that I have seen by either cellular companies or equipment manufacturers.

35. For instance, in New York NYNEX owned 54 percent, Bell Atlantic owned 36 percent, and Sprint owned 10 percent. NYNEX and Bell Atlantic subsequently merged their cellular operations. 
sequently used lotteries to award the nonwireline licenses in smaller MSAs and in rural areas, but it continued to award the wireline license to the wireline carrier. Overall, FCC indecision delayed the provision of cellular telephone in the United States by seven to ten years. This regulatory indecision made a new good, cellular telephone, unavailable in the United States when it was being offered in Scandinavia and Japan using equipment invented by AT\&T Bell Labs.

\section{Estimating the Cost of Regulatory Delay}

To approximate the consumer welfare loss caused by the FCC delay, I begin with the econometric estimation to implement the expenditure function approach of equations 5 and 6 and the linear approximation approach of figure 2 . To do so, I collected price and subscribership data for the period 1989-93 from a confidential survey of cellular operators and used the data to run a regression of cellular prices in the top thirty MSAs. These MSAs contain about 107 million people, or about 41 percent of the U.S. population. ${ }^{36}$ Table 3 presents an econometric analysis of cellular demand. Here the left-hand-side variable is the log of the number of subscribers, and the right-hand-side variable is the log of price along with variables for log of income, $\log$ of population, log of commute time, regulation, and year. The price variable is based on the monthly access charge and per minute charges for 160 minutes a month (the approximate average usage) for the least expensive plan available for 160 minutes of usage in each MSA. ${ }^{37}$ Monthly prices for average usage varied in the MSAs from a high of $\$ 125$ in New York City to a low of $\$ 55$ in Buffalo, with cellular carriers in Portland, Oregon, and Chicago also offering very low monthly prices. The price of the cellular telephone is also included, using a three-year amortization period based on an observed churn rate of 0.33 a year. The year variable allows for a diffusion curve effect and changes in prices of competing services,

36. Note that no truncation or sample selection bias is introduced by using the top thirty MSAs because population is an exogenous variable.

37. Cellular consumers typically have a variety of linear and nonlinear price schedules to choose from. I use the most economical plan for the average usage per month, consistent with my approach of using a representative consumer model. In calculating the consumer surplus measure, nonlinearities in the price schedules can be taken into account by the use of a "virtual income" measure, as in my previous research (Hausman, 1985), but no significant change occurs because of the very small size of virtual income compared with overall consumer income. 
Table 3. 1989-93 Demand Regression for Top Thirty Cellular Markets

\begin{tabular}{|c|c|c|}
\hline \multirow[b]{2}{*}{ Variable } & \multicolumn{2}{|c|}{ Regression method } \\
\hline & $\begin{array}{c}\text { Ordinary } \\
\text { least squares }\end{array}$ & $\begin{array}{c}\text { Instrumental } \\
\text { variables }\end{array}$ \\
\hline Intercept & $\begin{array}{c}0.852 \\
(2.475)\end{array}$ & $\begin{array}{c}1.101 \\
(2.478)\end{array}$ \\
\hline Log of pricel & $\begin{array}{r}-0.406 \\
(0.151)\end{array}$ & $\begin{array}{c}-0.506 \\
(0.169)\end{array}$ \\
\hline Log of income & $\begin{array}{c}0.184 \\
(0.302)\end{array}$ & $\begin{array}{c}0.193 \\
(0.302)\end{array}$ \\
\hline Log of population" & $\begin{array}{c}0.948 \\
(0.064)\end{array}$ & $\begin{array}{c}0.953 \\
(0.064)\end{array}$ \\
\hline Log of commute time & $\begin{array}{c}0.977 \\
(0.356)\end{array}$ & $\begin{array}{c}0.984 \\
(0.355)\end{array}$ \\
\hline Regulation & $\begin{array}{r}-0.161 \\
(0.065)\end{array}$ & $\begin{array}{r}-0.147 \\
(0.066)\end{array}$ \\
\hline Year 89 & $\begin{array}{c}-1.234 \\
(0.090)\end{array}$ & $\begin{array}{c}-1.217 \\
(0.091)\end{array}$ \\
\hline Year 90 & $\begin{array}{c}-0.830 \\
(0.078)\end{array}$ & $\begin{array}{c}-0.817 \\
(0.078)\end{array}$ \\
\hline Year 91 & $\begin{array}{c}-0.566 \\
(0.071)\end{array}$ & $\begin{array}{c}-0.559 \\
(0.071)\end{array}$ \\
\hline Year 92 & $\begin{array}{c}-0.310 \\
(0.069)\end{array}$ & $\begin{array}{c}-0.306 \\
(0.069)\end{array}$ \\
\hline Number of observations & 196 & 196 \\
\hline Standard error & 0.315 & 0.315 \\
\hline$R^{2}$ & 0.982 & - \\
\hline
\end{tabular}

Source: Author's calculation.

Notes: Standard errors in parentheses. Lefi-hand-side variable $=\log$ of subscribers.

a. Price is endogenous. Instruments include average price across other top thirty metropolitan statistical areas, an indicator variable for state regulation of paging, maximum marginal state income tax rates. state taxes as a percentage of personal income, and construction costs.

b. Minimum monthly bill is based on 128 minutes of peak calling and 32 minutes of off-peak calling.

c. Log of per capita personal income. Source: NPA Data Services. Inc.. April 1994.

d. Log of population. Source: NPA Data Services. Inc., April 1994.

e. Mean commute time from home to work. Source: 1990 U.S. Census, Tape File 3c.

such as paging. The least squares estimate of the price elasticity is -0.41 , which is estimated quite precisely (standard error $=0.15$ ). Note that the population variable estimate is 0.95 , which is not statistically different from 1.0 , as would be expected. A significant effect of commuting time in the MSA is also found to be important.

The right-hand column of table 3 shows a reestimation of the demand model using instrumental variables. This estimation methodology takes into account possible joint endogeneity of price and demand. When instrumental variables are used in the model, the demand elasticity is 
estimated to be -0.51 (standard error $=0.17) .{ }^{38}$ This somewhat higher elasticity estimate yields a somewhat smaller effect than the initial model for the gain in consumer welfare from the introduction of cellular. A Hausman specification test does not reject the elasticity estimate from the initial model. ${ }^{39}$ Note that the parameter estimates for the other variables, such as population, remain virtually the same. ${ }^{40}$

The expenditure function of equation 6 is calculated: ${ }^{41}$

$$
C V=\left[\frac{(1-\delta)}{(1+\alpha)} y^{-\delta}\left(p_{1} x_{1}-p_{0} x_{0}\right)+y^{(1-\delta)}\right]^{1 /(1-\delta)}-y .
$$

This equation is then used to calculate the compensating variation for the introduction of cellular telephone using the average revenue and subscribership data discussed earlier as well as the econometric estimates of the parameters of the demand function and associated expenditure function. The gain in consumer welfare from the introduction of cellular telephone is estimated to be $\$ 49.8$ billion a year (asymptotic standard error $=\$ 22.6$ billion) .

Next, the gain in consumer welfare is calculated using the linear approximation used previously for voice messaging. This approximation provides a lower bound estimate for the compensating variation. The larger of the two estimated price elasticities in table $3,-0.51$, is used to yield a lower bound approximation to the gain in consumer welfare from the introduction of cellular of $\$ 24.2$ billion a year (asymptotic standard error $=\$ 8.1$ billion). The gain in consumer welfare measured as the compensating variation from cellular is in the range of

38. One of my discussants raised the point of possible errors in variables from using the price for average cellular usage in the estimated demand equation. The instrumental variable procedure should eliminate the possible problem of errors in variables. Note that estimated price elasticity is a market (not firm) price elasticity, so an estimate of -0.51 is not "too low" given the limited substitute services to cellular telephone.

39. Hausman (1978).

40. I have done IV estimation to allow both price and regulation to be jointly endogenous. I find results similar to the previous estimates.

41. The results of Hausman (1981) are used to calculate the compensating variation. Here because the estimated price elasticity is less than one, the integral of the compensated demand function does not converge. To calculate the compensating variation from the introduction of cellular, I use the area under the compensated demand curve between the year in question, for $p_{1} x_{1}$, and 1985 , for $p_{0} x_{0}$, which is the beginning year of the CTIA data. This calculation slightly underestimates the gain in compensating variation. 
Table 4. Estimated Lost Consumer Welfare in 1983 Because of Cellular Telephone Delay (1994 Dollars)

\begin{tabular}{llcl}
\hline Scenario & Penetration & Assumed price & Lost welfare \\
\hline Similar to 1994 & 1994 level & 1994 price & $\$ 49.8$ billion \\
Higher price & 1994 level & $50 \%$ higher & $\$ 33.5$ billion \\
Lower demand & $50 \% 1994$ level & $50 \%$ higher & $\$ 16.7$ billion \\
\hline
\end{tabular}

Soruce: Author's calculations.

$\$ 24$ billion to $\$ 50$ billion a year, which demonstrates the substantial value to consumers from the introduction of cellular telephone.

The $\$ 24$ billion estimate is likely to be quite conservative, however. The linear approximation implies a virtual price of $\$ 97.09$ at current demand levels, which seems quite low for the monthly fee for users who achieve high utility from the mobility feature of cellular telephone. Indeed, the data set shows actual monthly fees as high as $\$ 125$, with substantial demand occurring at these prices. Holding other parameters constant, a virtual price of $\$ 125$ a month would lead to a lower bound estimate of consumer welfare of $\$ 31.2$ billion a year. Thus, a more refined estimate of the gain in consumer welfare from cellular telephone is in the range of $\$ 31$ billion to $\$ 50$ billion a year.

The same approach used for voice messaging can now be used to determine how much consumer welfare was lost by the ten-year delay in the introduction of cellular telephone caused by FCC indecision. I attempt to approximate this welfare loss by asking the question: If in 1983 cellular had already been available for ten years - as it would have been were it not for the FCC delays-but if, because of more limited and higher cost microprocessors and other semiconductor chips, it cost twice as much (in 1983 dollars) as it did in 1994, and correspondingly, if demand were lower because of the higher price, what was the lost consumer welfare? I estimate that the annual lost consumer welfare was approximately $\$ 24.3$ billion in 1983 dollars or about $\$ 33.5$ billion in 1994 dollars (table 4). Thus, the lost compensating variation was about $\$ 76$ per subscriber per month, which is equivalent to an average monthly service price (with the assumed 50 percent increase) of about $\$ 120$ per month. Even if I assume that demand for cellular would only have been half as great in 1983 as it was in 1994 because of decreased functionality, I still estimate an annual welfare loss of approximately $\$ 16.7$ billion. $^{42}$

42. Rohlfs, Jackson, and Kelley (1991) earlier estimated a welfare loss of about $\$ 85$ 
These findings reinforce a fundamental point: the consumer welfare cost of holding up the introduction of a new good is much larger than the effects of higher prices or other regulatory effects on demand, because the entire compensating variation is lost when regulatory delays cause demand to be zero. The welfare loss from the delay in the introduction of cellular is considerably larger than the delay in voice messaging, in part because the demand for cellular is approximately four times as large as the demand for voice messaging.

As these two studies show, regulatory delay can have potentially large negative effects on the U.S. economy. Why then did the FCC impose such harm on consumers and the economy? It appears that delay in cellular service was the commission's way to avoid confronting a very difficult decision. Potential losses in consumer welfare did not appear to figure into the FCC's regulatory approach. Indeed, the delay might have been even longer had cellular service not begun in other countries, which placed additional pressure on the FCC to reach a decision.

\section{Estimating a Telecommunications Price Index That Includes New Services}

An alternative approach to valuing these new telecommunications services involves calculating a cost-of-living index (COLI) for telecommunications services that includes cellular telephone and voice messaging services and then comparing this index to one that excludes these services. Because a cost-of-living index is a monotonic transformation of the expenditure function in the representative consumer model, its calculation determines the percentage improvement in utility for a subutility function of telecommunications services.

The Bureau of Labor Statistics (BLS) calculates a consumer price index for telephone services each month. Its major components are local access charges, intrastate long-distance (toll) charges, and interstate long-distance (toll) charges. The telephone service index is 1.7 percent of the overall consumer price index, but the telephone service index

billion from the delay in introducing cellular telephone in the United States, assuming the delay to be ten years. 
Figure 5. Telecommunications CPI: BLS and Corrected Cost-of-Living Increase (COLI) Calculations

Index

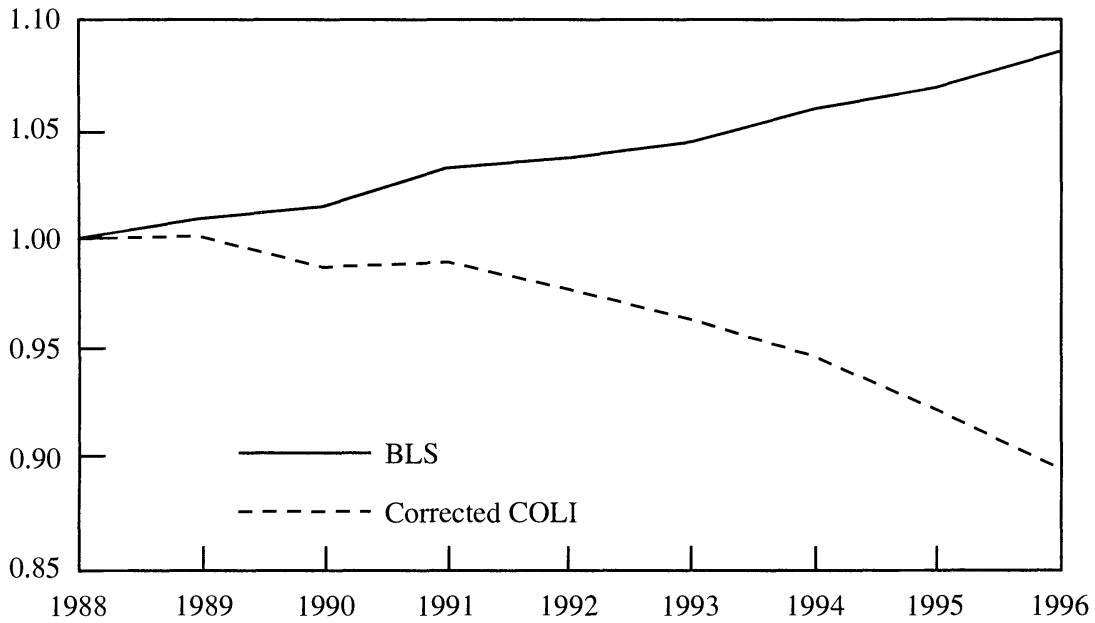

Source: Author's calculations; Bureau of Labor Statistics.

does not include cellular telephone and does not account for the gain in consumer welfare from the introduction of voice messaging services (although it takes the price change for messaging services into account).

To estimate an augmented price index that includes both these services, I take into account the decline in prices for cellular and voice messaging services as well as the gain in consumer welfare from the introduction of both services. To construct the augmented index, I use yearly expenditure weights based on total local and long-distance expenditure ${ }^{43}$ Figure 5 shows both the BLS index and my augmented one. Note that the BLS index estimates that telecommunications prices have increased by 8.5 percent since 1988 , an increase of 1.02 percent a year. The augmented index shows a decline, from 1.0 in 1988 to

43. To the extent that the proportion of consumer usage of cellular is approximately equal to consumer usage of local and long-distance services, these weights create a superlative price index; see Diewert (1976). Otherwise, the calculation leads to an approximation to a telecommunications CPI that would need data on consumer expenditure shares to become a superlative index. 
0.897 in 1996 , for a price decrease of 1.35 percent a year. ${ }^{44}$ Thus, the bias in the BLS index equals approximately 2.37 percentage points a year. Over the period 1988-96, the inclusion of these new telecommunications services decreases the change in the BLS index by about 20 percent, a significant amount both for a price index and as a measurement of the utility derived from telecommunications services.

\section{The Current FCC Approach to Regulating New Investment in Services}

"It's no fun to be a regulator unless you get to regulate."

Anon.

The Telecommunications Act of 1996 was the first basic change in the regulatory framework for telecommunications since 1934. It called for less regulation, more competition, and the most modern telecommunications infrastructure possible; its purpose was "to provide for a pro-competitive, de-regulatory national policy framework designed to accelerate rapidly private sector deployment of advanced telecommunications and information technologies and services to all Americans by opening all telecommunications markets to competition." 45 The FCC has instituted numerous regulatory rulemakings to implement the 1996 Telecommunication Act. The most important so far has been the Local Competition and Interconnection Order of August 1996. ${ }^{46}$ If implemented in its current form, this order will likely have serious negative effects on innovation, the introduction of new services, and new investment in the local telephone network.

Most economists agree that regulation should be used only when significant market power can lead to unregulated prices well above competitive levels. In these cases, the goal of regulators should be to

44. Approximately 95 percent of this change is due to the introduction of cellular telephone; the other 5 percent arises from the introduction of voice messaging services.

45. U.S. House. Conference Report to the Telecommunications Act of 1996, S. 652. 104 Cong. $2 d$ sess., 1996, H. Rept. 104-458.

46. FCC, “First Report and Order, CC docket No. 96-98 and 95-185,' August 1, 1996. The local exchange carriers are challenging the FCC order in federal court. Two questions are at issue: whether the FCC improperly usurped the rights of states to set regulated rates for local competition; and the validity of the pricing framework the FCC used to set the rates. Only the latter issue is considered here. 
set prices at "competitive levels." Economists are much less explicit, however, about how these competitive levels of prices can be estimated, particularly for telecommunications networks with large fixed costs. Most economists would agree that perfect competition cannot yield the appropriate standard because prices set at marginal cost will not allow a privately owned utility to earn a sufficient return on capital to survive. The large fixed costs of telecommunications networks thus do not allow the price-equals-marginal-cost standard of perfect competition to be used.

Baumol and Sidak have proposed an alternative competitive standard, the "perfect contestability" standard. Under this standard regulators would require firms to set prices as if "the competitive pressures generated by fully unimpeded and costless entry and exit, contrary to fact, were to prevail." ${ }^{47}$ Costless entry and exit, however, presumes no sunk costs, that is, costs that cannot be recovered upon exit by a firm. This assumption is extremely far from economic and technological reality in telecommunications where the essence of most investments is an extremely high proportion of sunk costs. Consider the investment by a local exchange carrier in a new local fiber optic network that can provide new broadband services and high speed Internet access to residential customers. Most of the investment is sunk because it cannot be recovered if the broadband network does not succeed. Thus, when either technological or economic uncertainty exists, "perfect contestability as a generalization of perfect competition" cannot provide the correct competitive standard. ${ }^{48}$

In a perfectly contestable market, if the return to an investment decreases below the competitive return, the investment is immediately removed from the market and used elsewhere. The actual economics of telecommunications investment could not be further from a perfectly contestable market, however. When fiber optic networks are constructed, they are almost entirely sunk investments. If their economic return falls below competitive levels, the firm cannot shift them to other uses because of their sunk and irreversible nature. Thus, the use of a perfectly contestable market standard fails to recognize the important

47. Baumol and Sidak (1994, pp. 28, 31 ff.).

48. This feature of sunk and irreversible investment has been widely recognized by economic research in the past ten years. See MacDonald and Siegel (1986) and, for a recent and comprehensive treatment, Dixit and Pindyck (1994). 
feature of sunk and irreversible investments - they eliminate costless exit.

Because of its failure to take into account the sunk and irreversible nature of investments, the contestable market model has nothing of interest to say about competition in telecommunications. An industry cannot be expected to behave in a manner that is fundamentally inconsistent with its underlying technological and economic characteristics. Thus, just as the large fixed costs of telecommunications networks do not allow the price-equals-marginal-cost standard of perfect competition to be used, the large sunk costs of telecommunications networks do not allow the costless-entry-and-exit standard of perfect contestability to be used.

Another way to consider the problem of setting regulated prices is to allow for the existence of the (all-knowing) social planner, an approach well known to graduate students through the Second Fundamental Theorem of welfare economics. Suppose the social planner were considering a new investment in a telecommunications network where sunk and irreversible investments are the norm. The social planner wants to maximize the value of the social welfare integral over time subject to uncertainty. The investment, however, is subject to both technological and economic uncertainty, so the cost of the investment may (randomly) decrease in the future, and demand uncertainty means that the social planner does not know whether the investment will be economic. In making an optimal decision the social planner will take into account the sunk and irreversible nature of the investment because the investment cannot be shifted to another use if the new service fails. In this case, assuming that sunk costs do not exist, which is the perfect contestability standard, will lead to incorrect decisions and decreased economic efficiency. Unfortunately, the FCC has adopted the contestability standard in determining regulatory prices for unbundled network elements.

\section{FCC-Mandated Costs for Unbundling}

Under the Telecommunication Act of 1996, the FCC required local exchange carriers to sell their unbundled facilities to their competitors at cost-based prices. ${ }^{49}$ The FCC did not permit any markup over cost;

49. The FCC decision is currently under appeal. In the FCC proceeding I provided testimony on behalf of the local exchange carriers. 
instead, it used an approach that attempts to estimate the total service, long-run, incremental cost on a forward-looking basis. ${ }^{50}$ TSLRIC, as it is called, attempts to solve the perfect competition problem that price cannot equal marginal cost by allowing for the fixed costs of a given service to be recovered. Although it allows for recovery of the cost of investment and variable costs of providing the service over the economic lifetime of the investment, TSLRIC makes no allowance for the sunk and irreversible nature of telecommunications investment, so it adopts the perfect contestability standard. The distinction between "fixed" costs, which are recoverable, and "sunk" costs, which are not, is crucial. By concluding that TSLRIC (TELRIC) is economically efficient because it allows the recovery of the fixed costs of investment, the FCC has chosen the incorrect standard for setting regulated prices. TSLRIC in this case will lead to less innovation, decreased introduction of new services, and decreased investment below economically efficient levels.

\section{The TSLRIC Standard and Investment in New Services}

The first and easiest example of the negative effect of the use of TSLRIC on the introduction of new services is investment in new services. Many new telecommunications services do not succeed. Recent failures include Picturephone services (AT\&T and MCI in the 1990s) and information service gateway services offered by many local exchange carriers. These new gateway services required substantial sunk costs in research and development to create the large databases necessary to provide information services. Now if a local exchange carrier introduces a successful new service, under proposed FCC rules, a competitor can buy the service at a price determined using the TSLRIC approach. At most, the local carrier will recover its cost-and not enough to cover the sunk investment in any unsuccessful services. If the FCC rule were applied to the pharmaceutical industry, pharmaceutical companies would be required to sell or license their successful products to generic producers or resellers at incremental cost. They would recover their $R \& D$ and production costs on their successful new

50. The FCC chose a variant of TSLRIC, called TELRIC for total element, longrun, incremental cost. The essential economic problem of TSLRIC also exists in TELRIC, however. 
drugs, but that is not enough to cover the costs of any unsuccessful attempts.

Because innovative projects in telecommunications have a significant probability of failure, this truncation of returns on successful new services decreases economic incentives for regulated telecommunications companies to innovate. By eliminating the right tail of the distribution of returns, the FCC has decreased the mean of the expected return of a new project. For example, consider a project with returns, $y$, that follow a normal distribution with mean $\mu$ and standard deviation $\sigma$. The expected value of the return when it is truncated at cost $c$ is:

$$
E(y \mid y<c)=\mu-\sigma M(c),
$$

where $M(c)$ is the inverse Mills ratio evaluated at $c .{ }^{51}$ Thus, the tighter the cost standard, the lower are the incentives to innovate, as expected. More important, note that as the returns to the innovation become more uncertain, the expected return and the incentives to innovate also decrease. Indeed, for any symmetric distribution of returns, including the normal, the FCC's TSLRIC approach could stop all new investments in uncertain services because for any service a local exchange carrier would undertake in the absence of regulation, $E(y)>c$, so truncation of the distribution at $c$ will cause $E(y)<c$, and no new investment may occur.

Thus, the issue of sunk and irreversible investments aside, the FCC pricing policy decreases the economic incentives for investment in innovative services and may eliminate them altogether. Consider the likely outcome if the FCC had used a TSLRIC approach to regulate the price of cellular telephone service. If cellular carriers had been required to sell their services to competitors (resellers) at a TSLRIC cost-based price, it is unlikely that they would have risked the billions of dollars of investment in cellular networks when the future of cellular was highly uncertain and many industry analysts did not forecast much success for cellular. The consumer welfare gains that have been derived from the success of cellular telephone would not have existed; indeed, a TSLRIC-based rule would likely have led to tens of billions of dollars of lost consumer welfare.

51. The inverse Mills ratio is the ratio of the density function and distribution function of the standard normal distribution evaluated at $(c-\mu) / \sigma$. The inverse Mills ratio $M(c)$ increases monotonically as $c$ decreases for given $\mu$ and $\sigma$. 
The FCC could apply something similar to patent protection for new services to give the local exchange carriers economic incentives to innovate in the presence of the TSLRIC-based pricing approach. ${ }^{52}$ But this policy option is a recipe for delay. Currently, the Patent Office takes more than two years to grant a patent, and longer time periods are not uncommon. No opponent of the patent is allowed to be part of the process, however. In an FCC setting, where competitors presumably would be permitted to participate, as they are now, and would likely attempt to delay the introduction of new services as they did with both voice messaging and cellular telephone, I would expect much longer delays. Thus, the patent approach will not solve the problem. A better approach would be to leave new services unregulated. The gains in consumer welfare from successful new services would lead to significant gains for consumers. Attempting to "fine-tune" prices of new services through cost-based regulation will lead to overall consumer losses. Regulators, however, find it extremely difficult not to regulate any new service of a regulated company.

\section{The Effect of Sunk and Irreversible Investments}

TSLRIC assumes that all capital invested now will be used over the entire economic life of the new investment and that prices for the capital goods or the service being offered will not decrease over time. ${ }^{53}$ With changing demand conditions, changing prices, or changing technology, these assumptions are not necessarily true. Thus, TSLRIC assumes a world of certainty when the actual world is one of uncertainty. Significant economic consequences can arise from the effect that the sunk nature of investment has on the calculation of TSLRIC.

Consider the value of a project under no demand uncertainty with a risk-adjusted discount rate of $r$, and assume a known exponential economic depreciation at rate $\delta$. This assumption on depreciation can be thought of as the price of the capital decreasing over time at this rate due to technological progress. Assume that price, net of the effect of economic depreciation of the capital goods, is expected to decrease

52. The FCC chief economist Dr. Joseph Farrell recently considered this option; see Farrell (1997).

53. This discussion follows Hausman (1996b). See also Laffont and Tirole (1996). 
with growth rate $-\alpha .{ }^{54}$ The initial price of output is $P$. The value of the project is

$$
V(P)=\int_{0}^{\infty} \lambda \exp (-\lambda t) P \frac{1-\exp (-\delta t)}{\delta} d t=P /(\lambda+\delta),
$$

where $\lambda=r+\alpha$. Note that $\delta$ is added to the expression to account for the decreasing price of capital goods. This term, omitted from the FCC's TSLRIC calculations, accounts for technological progress in equipment prices, which is one economic factor that leads to lower prices over time. Suppose that the cost of the investment is $I$. The rule for a competitive firm is to invest if $V(P)>I$. Equivalently from equation $9, P>(\lambda+\delta) I$. The economic interpretation of this expression is that the price (or price minus variable cost) must exceed the cost of capital, which includes the change in price of the capital good to make the investment worthwhile. ${ }^{55}$ Note that the net change in the output price and the price of the capital good both enter the efficient investment rule. The FCC's TSLRIC calculation ignores the basic economic fact that when technological change is present, (quality-adjusted) capital goods prices tend to decline over time. This economic factor needs to be taken into account, or economic inefficiency will result.

Now, a TSLRIC calculation does not include $\delta$ but instead assumes that the price of capital goods does not change over time. This assumption is extremely inaccurate. Take a Class 5 central office switch, for example. In the late 1980s an AT\&T Class 5 switch was sold to a Bell operating company for approximately $\$ 200$ a line. ${ }^{56}$ Today, these switches are priced at $\$ 70$ a line or lower. A TSLRIC calculation would be based on the $\$ 70$ price. A Bell operating company that paid $\$ 200$ a line made the efficient investment decision when it purchased its central office switch. But TSLRIC, by omitting economic depreciation caused by technological progress, leads to a systematically downward biased estimate of costs. Indeed, I estimate the economic depreciation of central office switches to be near 8 percent a year over the past five years, while the cost of fiber optic carrier systems has decreased at approxi-

54. This factor arises because of changes in demand and total factor productivity.

55. For simplicity, I assume only capital costs and no variable costs in this calculation. Variable costs can be included by reinterpreting $P$ to be price minus variable costs, which will lead to the same solution.

56. Hausman and Kohlberg (1989, p. 204). 
mately 7 percent a year during the same period. Technological progress can make the omitted economic factor $\delta$ quite large relative to $r$ for telecommunications switching or transmission equipment.

TSLRIC calculations assume that the investment is always used at full capacity, that the demand curve does not shift inward over time, and that a new technology does not appear that lowers the cost of production. Of course, these conditions are unlikely to hold true over the life of the sunk investment. Thus, uncertainty needs to be added to the calculation.

Given the fundamental uncertainty and the sunk nature of the investment, a "reward for waiting" occurs because over time some uncertainty is resolved. The uncertainty can arise from uncertainty about demand, price, technology, or interest rates. ${ }^{57}$ Now the fundamental decision rule for investment changes to

$$
P^{s}>\frac{\beta_{1}}{\beta_{1}-1}(\delta+\lambda) I,
$$

where $\beta_{1}>1$ so that $m=\beta_{1} /\left(\beta_{1}-1\right)>1$. The parameter $\beta_{1}$ takes into account the sunk cost nature of the investment coupled with inherent economic uncertainty. ${ }^{58}$ Parameter $m$ is the markup factor required to account for the effect of uncertain economic factors on the cost of sunk and irreversible investments. Thus, the critical cutoff point for investment is $P^{\mathrm{s}}>P$, from equation 9 .

To see how important this consideration of sunk costs can be, I evaluate the markup factor $m$. The parameters $\beta_{1}$ and $m$ depend on

57. The FCC incorrectly assumed that taking into account expected price changes in capital goods and economic depreciation is sufficient to estimate the effect of changing technology and demand conditions; see the FCC "First Report and Order," para. 686. Thus, the FCC implicitly assumed that the variances of the stochastic processes that determine the uncertainty are zero, that is, that no uncertainty exists. Under the FCC approach the values of all traded options should be zero (contrary to stock market fact), because the expected price change of the underlying stock does not enter the option value formula. It is the uncertainty related to the stochastic process as well as the time to expiration that gives value to the option, as all option pricing formulas demonstrate; the Black-Scholes formula is one example.

58. I do not derive this equation here because it is the solution to a differential equation. For a derivation, see, for example, Dixit and Pindyck (1994, pp. 254-56, $279-80,369)$. The parameter $\beta_{1}$ depends on the expected risk-adjusted discount rate of $r$, expected exponential economic depreciation $\delta$, the net expected price $-\alpha$, and the amount of uncertainty in the underlying stochastic process. 
several economic factors. As uncertainty increases, that is, the variance of the underlying stochastic process, $\beta_{1}$ decreases and the $m$ factor increases. Also, as $\delta$ increases, $\beta_{1}$ increases, which means that the $m$ factor decreases. As $r$ increases, $\beta_{1}$ decreases, so the $m$ factor increases. MacDonald and Siegel and Dixit and Pindyck calculate $m=2$, so, for instance, $V^{\mathrm{S}}=2 I .{ }^{59} \mathrm{~A}$ TSLRIC calculation that ignores the sunk cost feature of telecommunications network investments would thus be off by a factor of two.

Using parameters for local exchange carriers and taking into account the decrease in capital prices caused by technological progress (which Dixit and Pindyck assume to be zero in their calculation) and because the expected change in (real) prices of most telecommunications services is also negative given the decreasing capital prices, I calculate the value of $m$ to be 3.2-3.4. ${ }^{60}$ Thus, a markup factor must be applied to the investment cost component of TSLRIC to account for the interaction of uncertainty with sunk and irreversible costs of investment. ${ }^{61}$ Depending on the ratio of sunk costs to fixed and variable costs, the overall markup on TSLRIC will vary, but it will be significant given the importance of sunk costs in most telecommunications investments. Note that this same markup over TSLRIC would be used by the hypothetical social planner to choose optimal investment in a telecommunications network because the social planner would face the same inherent economic and technological uncertainty over future demand and cost factors.

59. MacDonald and Siegel (1986) and Dixit and Pindyck (1994, p. 153).

60. Because of the expected decrease in the price of capital goods, even if the standard deviation of the underlying stochastic process were 0.25 as high as a typical stock, the markup factor would still be 2.1 . For a standard deviation 0.5 as high, the markup factor is 2.4. I have also explored the effect of the finite expected economic lifetimes of the capital investments in telecommunications infrastructure. Using expected lifetimes of ten to fifteen years leads to only small changes in the option value formulas; for example, for a project with a twelve-year economic life, the markup factor of 2.0 changes to 1.9 .

61. It is the advent of competition that requires correct regulatory policy to be applied to the markup. Previously, when regulatory policy did not allow for competition, regulators could (incorrectly) set prices based on historic capital costs. Given the onset of competition arising from the 1996 Telecommunication Act and regulatory removal of barriers to competition, regulators must now account for changes in prices over time. Otherwise, local exchange carriers will decrease their investment below economically efficient levels because their expected returns, adjusted for risk, will be too low to justify the new investment. 
By failing to apply a markup to TSLRIC, the FCC has set too low a regulated price for telecommunications services from new investment, and the result will be a decrease in new investment in telecommunications services and network infrastructure below economically efficient levels, contrary to the stated purpose of the Telecommunications Act of 1996. If a goal of the FCC is to achieve facilities-based competition in local telecommunications, it has failed in its task. It has set prices that will decrease the incentives of potential competitors to construct their own networks because TSLRIC always makes it more attractive to "rent" than to "buy" a telecommunications network. Similarly, the FCC has decreased the incentives for new competitors to invest in innovative services because they can wait for the local incumbents to invest and then demand access to successful new services at cost. Through its focus on static cost efficiency considerations in setting regulated prices equal to TSLRIC, the FCC has missed the negative effect on dynamic efficiency that TSLRIC-based prices will cause. The examples of voice messaging and cellular telephone demonstrate the large dynamic efficiency effects in telecommunications that will be lost if the FCC's use of TSLRIC to set regulated prices is permitted to go forward.

\section{Conclusions}

New telecommunications services can create very large gains in consumer welfare. For voice messaging services I estimate consumer welfare gains of about $\$ 1.27$ billion a year based on current levels of demand and price. For cellular telephone those gains are about $\$ 50$ billion a year. Regulation, which has led to lengthy delays in the introduction of new telecommunications services, thus causes very large losses in consumer welfare. Note that these losses in consumer welfare cannot be regained in subsequent periods. ${ }^{62}$

62. I have considered possible consumer losses due to possible cross-subsidy from other regulated services in Hausman and Tardiff (1995). Using the demand function parameter estimates from Hausman, Tardiff, and Belinfante (1993), the possible welfare losses are quite small because the estimated price elasticities for these regulated services are very near to zero. I estimate the potential welfare loss to be less than $\$ 100,000$, compared with the welfare gain of more than $\$ 1$ billion. Thus, consumer gains from new services are very large compared with possible consumer losses. Further details of these calculations will be provided upon request. 
Unfortunately, regulators do not seem to have recognized the large consumer welfare losses from past regulatory delays and pricing distortions. The FCC's recently adopted TSLRIC approach to pricing creates significant negative economic disincentives to investment in new services or new infrastructure by regulated telephone companies or by their competitors. The FCC has based its pricing framework on an incorrect economic model that neglects the important role of sunk and irreversible investments in telecommunications. Thus, the FCC has once again focused on static cost efficiency questions and failed to account for the demonstrated large gains in dynamic economic efficiency that arise from new investment. Through its regulatory actions, the FCC has decreased the chances that U.S. residential customers will have access to broadband fiber networks in the near future, whether offered by local exchange carriers or by competitive new entrants. By setting network prices below competitive levels, the FCC has discouraged the local exchange carriers from new investments in infrastructure. It has also discouraged new entrants from investing in their own infrastructure because they can buy the services at below-competitive prices and less risk from the carriers.

Regulation, as currently implemented, may well be unable to keep up with the fast-paced changes in telecommunications technology. Consumer welfare losses are likely to be quite large because of regulatory delays and pricing distortions. Past welfare losses have been in the billions of dollars per year, and the FCC's current approach may well lead to comparable consumer welfare losses in the future.

\section{References}

Baumol, William J., and J. Gregory Sidak. 1994. Toward Competition in Local Telephony. MIT Press.

$\rightarrow$ Berry Steven, James Levinsohn, and Ariel Pakes. 1995. "Automobile Prices in Market Equilibrium." Econometrica 63 (4): 841-90.

Calhoun, George. 1988. Digital Cellular Radio. Norwood, Mass.: Artech.

$\rightarrow$ Diewert, W. E. 1976. "Exact and Superlative Index Numbers." Journal of Econometrics 4 (May): 115-46.

Dixit, Avinash K., and Robert S. Pindyck. 1994. Investment under Uncertainty. Princeton University Press. 
Farrell, Joseph 1997. "Competition, Innovation, and Deregulation." Paper presented at Harvard University. April.

$\rightarrow$ Hausman, Jerry A. 1978. "Specification Tests in Econometrics." Econometrica 46 (November): 1251-71.

$\longrightarrow \rightarrow$. 1980. "The Effect of Wages, Taxes, and Fixed Costs on Women's Labor Force Participation.' Journal of Public Economics 14 (October): 16194.

$\longrightarrow \rightarrow$ 1981. "Exact Consumer's Surplus and Deadweight Loss." American Economic Review 71 (September): 662-76.

$\longrightarrow \rightarrow$. 1985. "The Econometrics of Nonlinear Budget Sets." Econometrica 53 (November): 1255-82.

. 1996a. "Valuation of New Goods under Perfect and Imperfect Competition." 'In The Economics of New Goods, edited by Timothy S. Bresnahan and Robert J. Gordon. University of Chicago Press.

. 1996b. "Reply Affidavit of Prof. Jerry Hausman, FCC CC Docket No. 96-98," July.

Hausman, Jerry A., and Elon Kohlberg. 1989. "The Future Evolution of the Central Office Switch Industry." In Future Competition in Telecommunications, edited by Stephen P. Bradley and Jerry A. Hausman. Boston: Harvard Business School Press.

$\rightarrow$ Hausman, Jerry A., and Whitney K. Newey. 1995. "Nonparametric Estimation of Exact Consumer Surplus and Deadweight Loss." Econometrica 63 (November): 1445-76.

Hausman, Jerry A., and Timothy Tardiff. 1995. "Benefits and Costs of Vertical Integration of Basic and Enhanced Telecommunications Services." Massachusetts Institute of Technology.

$\rightarrow$ Hausman, Jerry A., Timothy Tardiff, and Alexander Belinfante. 1993. "The Effects of the Breakup of AT\&T on Telephone Penetration in the United States." American Economic Review 83 (May): 178-84.

$\rightarrow$ Hausman, Jerry A., and William E. Taylor. 1981. "Panel Data and Unobservable Individual Effects." Econometrica 49 (November): 1377-98.

$\rightarrow$ Hicks, J. R. 1940. "The Valuation of the Social Income." Economica 7: 10524.

Joskow, Paul L., and Nancy L. Rose. 1989. "The Effects of Economic Regulation." In Handbook of Industrial Organization, vol. 2, edited by Richard Schmalensee and Robert D. Willig, pp. 1449-1506. Amsterdam: North Holland.

Laffont, J. J., and J. Tirole. 1996. "Competition in Telecommunications." University of Toulouse. November.

Lee, William C. Y. 1982. Mobile Communications Engineering. McGraw-Hill.

$\rightarrow$ MacDonald, Robert, and Daniel Siegel. 1986. "The Value of Waiting to Invest."' Quarterly Journal of Economics 101 (November): 707-28. 
Malinvaud, Edmond. 1971. Statistical Methods of Econometrics, 2d rev. ed. Amsterdam: North Holland.

$\rightarrow$ Neary, J. P., and K. W. S. Roberts. 1980. "The Theory of Household Behavior under Rationing."' European Economic Review 13: 25-42.

$\rightarrow$ Oster, Sharon M., and John M. Quigley. 1977. "Regulatory Barriers to the Diffusion of Innovation: Some Evidence from Building Codes." Bell Journal of Economics 8 (Autumn): 361-77.

Rey, R. F., ed. 1983. Engineering and Operations in the Bell System. Murray Hill, N.J.: Bell Telephone Laboratories, Inc.

Rohlfs, Jeffrey H., Charles L. Jackson, and Tracey E. Kelley. 1991. "Estimate of the Loss to the United States Caused by the FCC's Delay in Licensing Cellular Telecommunications." National Economic Research Associates, Washington, D.C.

$\rightarrow$ Romer, Paul. 1994. "New Goods, Old Theory, and the Welfare Costs of Trade Restrictions." Journal of Development Economics 4 (1): 5-38.

$\rightarrow$ Rothbarth, E. 1940-41. "The Measurement of Changes in Real Income under Conditions of Rationing."' Review of Economic Studies 8: 100-7.

Rothenberg, Thomas. 1973. Efficient Estimation with A Priori Information. Yale University Press.

$\rightarrow$ Vartia, Yrjo. 1983. "Efficient Methods of Measuring Welfare Change and Compensated Income in Terms of Ordinary Demand Functions." Econometrica 51 (January): 79-98. 


\section{Comments}

Comment by Ariel Pakes: The basic argument made in this paper is that the Federal Communications Commission (FCC) currently behaves as if there is little cost to delaying the introduction of new goods. There are no institutional mechanisms, no incentives, explicitly designed to ensure that new goods are introduced in a timely fashion. Consequently "regulatory delay" in introducing new goods can result from any of a number of reasons, reasons that, if measured against the losses society implicitly incurs as a result of the delay, would seem quite inconsequential.

One element needed to prove this argument is a reliable measure of the gains from new goods (or, better yet, the losses from keeping them off the market). Indeed, such measures would likely be needed more generally, say, to design incentive mechanisms to allocate resources to overcome regulatory delay in the future. What this paper does is provide one technique for measuring the benefits from the introduction of new goods and applies it to analyzing society's losses from the regulatory delays in the introduction of phone messaging services and cellular phones.

I want to address the issues touched on in the paper at several different levels. First, the real importance of this paper lies in its raising the issue in the first place. The losses from regulatory delay are potentially large, and the paper deserves accolades from the profession for pointing this out. Second is the issue of the rough order of magnitude for the losses caused by regulatory delay for the two examples analyzed in the paper. There are good reasons to believe that, at least, the paper's lower bound results are essentially correct. Moreover, the magnitude of these (and the possibility of similar results for related products in 
this fast-moving industry) are large enough to justify a hard look at the agency causing the regulatory delay. In that sense, then, this paper should serve as a "wake-up" call to the FCC.

The other issues raised in this paper are, in my view, treated much less satisfactorily. First, almost half the paper is devoted to presenting a particular procedure for measuring consumer surplus gains from the introduction of new goods. I am not convinced either that the general strategy presented here is always sensible or that the techniques used in the current analysis are the best possible (even when the general strategy is sensible). Indeed, as I will explain, my belief in the results presented for the current examples relies more on the author's "back of the envelope" calculations than on the results from the econometric analysis.

Second, the paper concludes with two digressions; one applying the results to correct the consumer price index (CPI) for telecommunications services, and one evaluating the current FCC approach to the regulation of new investments. Although the telecommunications CPI is biased by the inadequate treatment of the introduction of voice messaging and cell phones, for reasons I detail later I do not have confidence in this paper's estimate of the "lower bound" to this bias. And although I am not happy with the new investment regulations for reasons similar to those given in this paper, I think there are much better ways to evaluate alternative policies than those proposed here.

Finally, the paper does not address the question of whether there were any benefits to regulatory delay and how these benefits match up against the total costs (which should include, in addition to the losses in consumer surplus estimated here, both the lost producer surplus and a measure of the loss in consumer and producer surplus from innovations that are not developed because the regulatory delay in these innovations changed the perception of the profitability of future inventions). There are at least three possible costs.

First, the introduction of the new good could have negative repercussions on the consumer surplus being generated from markets for related products. The concern should not focus so much on the possibility of tying or other arrangements that can be handled by regulation (albeit at a cost), but rather on "unilateral" pricing models and the possibility that the firm that introduces the new good will have an 
incentive to increase the price of related products. This is unlikely if the related good is a complement to the good introduced, for then standard theory would indicate that the introduction of the new good would lower the price of the related good, if it has any effect at all (this is the case in the voice messaging example below). If the two goods are close substitutes, however, a price increase for the related good is possible. In this case an analysis of a demand system that includes both goods may be required to determine the likely size of the price increases to existing alternatives and how the resulting consumer losses match up to the gains from the introduction of the new good (see the cell phone example below).

Second, although there may be an immediate gain in consumer surplus from an earlier introduction of the new good, the introduction may lead to a loss in future consumer surplus by allowing one firm to gain a dominant position that would allow it to charge higher prices in future years than would result from the market situation that might develop if there were delay. In evaluating this argument, keep in mind that society is not giving up its power to regulate the market for the new good in the future if the need arises and the firm realizes this (there is a cost to subsequent regulation, however).

Third, early introduction of the new good may harm the producer by inducing it to make sunk investment decisions on the basis of a perceived set of rules that are later changed. Keep in mind here that so long as the FCC is "up front" about its current thoughts regarding future regulation, then the firm is likely to be better able to evaluate the risks to its future profits from introducing the good than the regulator is.

To the extent that these latter costs are possible, one needs a dynamic model to evaluate them (and I will point to one such model below). But it is hard to see how a "benevolent" regulator would let any of these costs get too large, and the estimated benefits from the introduction of new goods are quite large.

\section{Procedures for Evaluating New Goods}

In one sense the tools used here are among the most familiar tools of economics; the tools for analyzing demand systems. Typically, however, demand systems have been used to evaluate price elasticities, and 
the problems incurred in using these systems to analyze the benefits of introducing new goods are likely to be both different and hard to come to grips with.

It might well be argued that the details of estimating a demand system are of secondary importance when all one is after is own- and crossprice elasticities, particularly if one uses a sufficiently general functional form and has a reasonable procedure for worrying about the endogeneity of prices. Any sufficiently flexible functional form should get approximately the same predictions for these elasticities, according to this argument, at least for elasticities at points near the center of the data (which is usually where economists prefer them). ${ }^{1}$

Once a welfare analysis for the introduction of new goods is conducted, however, more is needed than slopes in a region of interest. Consumer surplus analysis requires an integral under the demand curve across a price range never observed. This typically will be determined largely by a set of assumptions that project the implications of the data into an "unobserved" range. As a result, assumptions play a bigger role in this type of analysis, so one should think harder about the implications of those that are made. ${ }^{2}$

Two general demand frameworks have been used to evaluate the benefits from new goods. One defines preferences directly on products, generating a demand system in "product space" (this is the framework used here). ${ }^{3}$ Alternatively preferences can be defined on the characteristics of products, and then demand for products determined based

1. The real problem that arises here is the dificulty of using a general functional form when the demand system has many goods. This is because the number of "parameters" needed to estimate (or the dimension of the function that needs to be approximated) increases geometrically in the number of goods. The solution is generally to restrict the relevant functions, but this raises the question of what the restrictions do to the quality of the approximation. With respect to this study, I argue that it would have been better to use a multiproduct demand system rather than the single product system used here, but, at least at the level of aggregation used in this study, the number of goods needed seems to be small.

2. Just because it is difficult to evaluate the benefits from the introduction of new goods does not mean that the evaluation should not be done. Indeed, as this paper stresses, failing to consider those benefits often allows policymakers to assume implicitly that there are none, and even simple back-of-the-envelope calculations typically indicate that this assumption is grossly misleading.

3. It was also used in a more sophisticiated way for cereals; see Hausman (1996). 
on the bundle of characteristics that are embodied in the marketed products. ${ }^{4}$

If the analysis is done in product space, the demand (or utility) function parameters can be estimated only after the good is introduced. As a result the cost of regulatory delay can be analyzed only after the delay. In characteristic space it is possible (although often difficult) to assess demand before product introduction. Because this is what is needed to help regulators solve their problems, there is a distinct advantage to working in characteristics space. ${ }^{5}$

Demand analysis also differs substantially between those who use a "representative agent" assumption, wherein the demand system is derived from the utility function of a single consumer who consumes all varieties of all goods, ${ }^{6}$ and techniques that derive aggregate demand by summing the demands from a distribution of utility functions. This paper uses the representative agent framework, which rules out, a priori, any analysis of distributional effects - and distributional implications are often especially important to regulators who must satisfy different interest groups. Moreover, in many ways the representative agent framework has unreasonable implications; notably, it can handle the advantages of variety only by building them into the cross derivatives of a single agent's utility function, a procedure that often leads to conclusions at odds with common sense.

Again incorrect models that fit data well and are reasonably good at approximating objects of interest in the range of the data can give inplausible results when used to predict demand in a range never observed (as one typically does when using the model to evaluate the benefits from new goods).

\section{Data and Analysis: Voice Messaging}

I begin with the problems with the demand system estimated. Because the same system is estimated for cellular, I do not have to go

4. See Berry, Levinsohn, and Pakes (1995) for the estimation problem, and Pakes, Berry, and Levinsohn (1995) for the application to evaluating the benefits of new goods.

5. To allow for product-specific constant terms, that constant term must be projected onto the observed characteristics and then the properties of the distribution of the residual from that projection must be considered before the standard errors of the estimates can be evaluated; see Berry, Levinsohn, and Pakes (1995).

6. See the review in Deaton and Muellbauer (1980). 
over these problems twice. I then point out why, despite the problems, I find the results convincing.

First, this is a one-good system. To a large extent the benefits of voice messaging are determined by comparisons to answering machines, so a demand system should compare voice messaging with answering machines. The author claims that the price of answering machines is (approximately) picked up by the state dummies and time trends, but even if it is, so are many other things, and for part of the analysis the price must be separated out. Second, even for a one-good system, the log-log form is extremely limited. Indeed, in one sense it cannot be true generally, at least not without income elasticities of one (else budget shares eventually exceed one). The estimated income elasticities are near five with $t$-values of ten, indicating that this approximation has to fail somewhere. Another indication that the form is not quite good enough comes from the inability to solve for the "virtual" price in this system (it is infinite). I also worry about the instruments. Although they push the estimates in the right direction, it is not clear they go far enough. What the instruments pick up is year shocks to the system; the paper interprets these as supply shocks, but they could well contain common demand shocks (which would generate a bias).

The paper attempts to skirt the problem of approximating the demand system in the region of the data and then using the approximation outside of that region by employing a simpler linear approximation to generate a lower-bound estimate to the consumer surplus. There are advantages to this type of analysis. First it requires fewer assumptions than does the full analysis; all that is required is an estimate of the elasticity of demand (at the midpoint of the data) and the assumption that demand curves are convex to the origin (everywhere). Given this, I would have preferred an estimate of the needed elasticity that depended on fewer assumptions than those used in the current analysis. Even so, the convexity assumption would be questionable. Econometric experience is largely from estimating log-log forms that assume convexity (they do not show convexity). Importantly, in a nonrepresentative agent framework, the convexity of the demand curve depends on the distribution of consumer attributes at the point, and for traditional distributions it changes signs as price changes.

This back-of-the-envelope calculation has another benefit, however. It introduces a lower bound to both the average and the maximum 
consumer surplus gain. These are relatively easy objects to form priors on. Moreover, I found the results here quite convincing. The lower bound to the virtual price (or maximum consumer surplus) is estimated to be $\$ 5$ above the actual price, or $\$ 13$ a month. It is hard to imagine that the consumer with the most utility increment from voice messaging would not find an increment of at least $\$ 5$ (it provides more services than answering machines and does not break down or run out of batteries), and the implied average numbers are also convincing.

The rest of the paper's calculations on the costs of the five- to sevenyear delay strike me as being overly conservative for at least two reasons. First, the effect of allowing either AT\&T or the local exchange carriers to market messaging services would have been to provide an incentive for these same companies to lower local or long-distance service prices, not raise it (I am assuming that the messaging services and other phone services are complements, and it is hard to imagine why they would not be). That is, had voice messaging been allowed sooner, additional gains in consumer surplus might have accrued through a fall in other telephone prices. Second, the paper assumes that the price would have been higher by 50 percent and that the price and quality of competing goods would have remained unchanged. Because of technological changes in answering machines, this probably underestimates the benefits of voice messaging.

Hence the $\$ 1$ billion loss estimate seems, if anything, implausibly low. This is an instance where one really wonders what the goals of the FCC and the judiciary system were.

\section{Cellular Telephony}

The problems with this set of estimates are almost identical to those for voice messaging, with two major differences. First, the market for cell phones is much larger than the market for voice messaging services. Second, in this example the competing products that should be included in an estimated system are car phones and wired (local and longdistance) usage. As a result the products already owned by the potential suppliers of the new good were substitutes for it. Consequently, regulators might legitimately worry that the supplier of the new good would find it profitable to raise the price of the already existing goods. Thus having estimates from a more complete demand system (with cross- 
price elasticities) would have been quite helpful; even if the estimates of consumer surplus losses as a result of the delay in offering cell phones are believable, the extent to which price increases in other phone services might have counterbalanced the positive effects of the introduction of cellular cannot be judged without some estimate of cross-price elasticities. Conversely, phone prices were largely regulated during this period, so the cross-price effect is unlikely to have been too much of an obstacle.

The lower-bound procedure provides an estimate of the virtual price of about $\$ 100$ a month (because the price elasticity is less, in absolute value, than -1 , the estimate that comes from integrating the area under the demand curve is infinite). It is hard to imagine that the businessperson who most values a cell phone does not value it at more than a $\$ 100$ a month. There is a question of the linearity of the approximation from the midpoint to the axis, but on the whole I did not have trouble with the lower bound to average consumer surplus.

These numbers, when combined with the size of the market, resulted in staggering estimates for the consumer surplus loss; on the order of $\$ 20$ billion. These are larger numbers than economists are used to in analyzing the costs of regulation, and they are reason to think hard about the regulatory process for the introduction of new goods (it is not clear, for example, that less should be spent on examining regulatory procedures than is spent on examining potential mergers).

\section{The CPI and the Regulation of New Investment}

I was less happy with these last two sections of the paper. First, the CPI adjustment is an adjustment for consumers, and the demand curves that were estimated were based on total (consumer and business) demand. Business demand is likely to be both a large and a relatively inelastic part of total demand for these services. As a result the appropriate CPI adjustment may well be smaller than the one provided. The last section considers the FCC's new regulations to force local exchange companies to unbundle their networks and sell their services at something like LRIC (long-run incremental cost) to its competitors. The paper asserts that the new pricing rules will retard innovation to the deteriment of society. Although I think this is likely to be the case, the 
analysis in the paper, particularly that of the likely impacts of alternative policies, is at best seriously incomplete.

First, the effects of these new rules are going to depend on who is producing the innovations. To the extent that the equipment producers are not the local exchange carriers and are therefore free to charge whatever the market will bear for their equipment, the effects are not likely to be so disastrous. Moreover, to the extent legally possible, the in-house development that the local exchange carriers now engage in (the production of data bases, for example), would likely be outsourced if rules such as these were enforced. Even in such cases, however, the implied change in market structure might well generate additional costs (that is, from a cost-minimization point of view, it might have been better to have the research and production firms housed in the same company).

Second, there is a question of available alternatives. The paper correctly refers to the benevolent social planner as a reference point (presumably one who attains all the necessary information costlessly and faces no incentive problems so that economic agents do exactly what they are told to do). Such a social planner would set price equal to marginal cost, charge a head tax (or some other tax that does not distort incentives), and then use the proceeds of this tax to fund investment and entry of an optimal amount.

This institutional setup is not likely to emerge, which means that the pros and cons of alternative institutional setups must be weighed. The paper does not provide a tool for doing that, however. Thus, I was not convinced by either the argument against patents (after all, patents are the current second-best choice for many industries that are technologically successful, and some of them, like the drug industry, have regulatory burdens that seem more imposing than those in telecommunications), or the option pricing formula (the author needs to show, for example, that the price process implicit in this calculation is consistent with a reasonable model for market and regulator interactions).

Moreover, the pros and cons of allowing the local exchange carriers to set prices freely must depend on the extent to which other ways of accessing the local market will become available. If they do (and there is an interrelated question of how many alternatives are optimal to develop), then the problems caused by the local exchange carriers' 
control of access to the markets are likely to be smaller. If alternatives do not become available, then the local exchange carriers will have monopoly power in access to the local market (which is just what everyone was trying to avoid).

The issues here are so complex that sensible evaluations seem impossible without discussing explicit institutional structures and actually computing out their implications. A framework for evaluating the pros and cons of alternative institutional frameworks in industries with large sunk costs has been built with just this situation in mind. ${ }^{7}$ It is an algorithm for computing Markov perfect equilibria in oligopolistic industries. ${ }^{8}$ The algorithm takes a current profit function as well as measures of sunk costs as inputs, computes a sequential equilibrium in investment, entry, and exit policies for all incumbents and potential entrants, and compares the consumer and producer surplus generated by the equilibrium with the results from a benevolent social planner's program. The profit, investment, entry, and exit parameters can be changed to reflect different institutional structures. A limited version of this algorithm is publicly accessible. ${ }^{9}$ One might want to modify the basic model to provide a closer approximation to the technological and institutional structure of the telecommunications industry, but even as the algorithm currently stands, it permits a far more detailed look at policy options than those that have been considered to date.

Comment by Gregory L. Rosston. This paper by Hausman points out important factors for regulators to keep in mind as they move forward in a world of uncertainty. ${ }^{10}$ First, new services can provide significant value to consumers. Second, uncertainty and sunk costs are important factors in the investment decision process. The obvious conclusion is that regulators should be careful not to inhibit innovation artifically either explicitly through prohibitions on service provision as in the

7. See Pakes and McGuire (1994).

8. See Maskin and Tirole (1988a, b).

9. There is a link to it on my web site and both a read-me file, and a postscript description of the algorithm, to start you off.

10. This comment was written while the author served as deputy chief economist of the Federal Communications Commission. The opinions expressed are those of the author and do not necessarily reflect those of the commission or any individual commissioner. 
voice mail context or implicitly through failure to allow firms to charge prices that will adequately compensate them for their investments.

\section{Introduction of New Services}

The benefits from the introduction of new services are extremely important to consumers and the economy. By providing quantitative estimates of the level of the benefits, regulators and legislators should have a better understanding of the trade-offs they are forced to make. In making their decisions, however, policymakers must also consider the costs of their decisions; additional work on the quantitative evidence of the costs of deregulation would also be useful. For example, what is the magnitude of the risk if a potentially competitive service is monopolized? What is the harm if a firm shifts costs from regulated to unregulated services?

The paper illustrates that benefits from the introduction of new services can be considerable and that regulators should be very careful not to delay these benefits needlessly. But overzealous deregulation may also entail costs. The concern about deadweight loss for consumers with a very low elasticity of demand for local service is probably not high, but there may be large wealth transfers from consumers to producers if safeguards to prevent cost shifting or discrimination are not in place. In addition, competition could be undermined if an incumbent uses its position in the local exchange to harm competitors (and hence consumers) in other related lines of business.

The "what if" analysis quantifying the lost consumer surplus assumes the world would have been exactly the same if the Federal Communications Commission (FCC) had only acted sooner. In analyzing both voice mail and cellular service, the paper calculates consumer welfare assuming that prices would have been higher and penetration correspondingly lower if the service had been introduced earlier. Several other factors that might have led to a significantly different environment had decisions been made earlier add uncertainty to the results, however. The paper assumes a ten-year delay for the introduction of cellular services. The FCC's final allocation decisions for cellular occurred in 1981. Earlier decisions in 1974 and 1975 would have allocated the cellular spectrum to a single operator. As a result, a counterfactual that looks at the cost of delay might also include the idea that instead 
of the duopoly competition for cellular, there might have been a single monopoly operator. Not all of the effects of delay turn out to be negative because information revealed over time can improve decisions. In fact, as the second half of the paper indicates, there is some option value to waiting to invest.

A more picky point is that the counterfactual may indeed underestimate the changes in cost that have occurred over the time period of delay. Increases in microprocessor power have had a significant impact on the cellular telephony market in a variety of ways. Processors are used in the switches (the paper states that the price declined from $\$ 200$ in 1989 to $\$ 70$ in 1996 , meaning that the introduction seven years earlier would have entailed a price increase of nearly 200 percent, not 50 percent as used in the paper. Handset costs declined from $\$ 2,600$ in 1983 to $\$ 250$ in 1991 , meaning that handsets would have cost on the order of 1000 percent more if there had been an earlier introduction. Other components of cellular service such as site leases and sales costs would not have been so different in cost, but the choice of 50 percent may be far too low in a dynamic environment.

The paper blames all of the delay in the introduction of these services on the FCC. I believe that to be an overstatement, not just because I worked there, but because in reality there appear to be possible alternative or complementary explanations for the delay in the introduction of these services. Put in a larger perspective, the introduction of voice mail could have been viewed as a way of trying to open up the local exchange to competition. At the time that the Bell operating companies wanted to introduce voice mail on an integrated basis, they were also fighting attempts to implement open network architecture and comparably efficient interconnection. By withholding permission to provide voice mail services, the FCC might have created more incentive for the operating companies to open up their networks to competition.

The benefits from open local exchange competition may swamp the voice mail estimates (they also may not). It is possible that regulators at the time had an idea of the value of voice mail services and thought that the loss was worth the possibility that they could induce more open local exchange competition. In fact, Congress made such a trade-off in the Bell operating company long-distance entry provisions of the Telecommunications Act. The operating companies cannot begin to provide in-region long-distance service until they satisfy a fourteen-point check- 
list to ensure that the local market is open to competition. The introduction of a new competitor in long-distance is likely to provide competitive benefits. Congress, however, was justifiably worried about competitive concerns arising from premature entry and, at the same time, wanted to use long-distance entry as a "carrot" to attain the benefits of local exchange competition as well as additional longdistance competition. Although these "deals"' may prove in hindsight to be bad for consumers, it is possible that Congress and the FCC expected the additional benefits from local competition to outweigh the losses from delaying entry of the Bell operating companies.

\section{FCC Pricing under the 1996 Act and Incentives for Investment}

The paper also looks at the pricing standards under the FCC's Local Competition Order. This portion of the paper examines the ideas behind ways to set prices for unbundled elements. The Telecommunications Act states that the price for unbundled elements is to be "based on the cost. . . , [be] nondiscriminatory, and may include a reasonable profit.",

This section of the paper also brings up important and valid concerns for a regulatory agency to consider. Unfortunately, it inaccurately portrays the nature of the FCC rules and pricing standards. The FCC order incorporates measures that allow state regulators (who are required under the act to set the actual rates) to account for uncertainty and the sunk and irreversible nature of investment.

Two important claims in this section should be kept distinct. First the paper claims that the TELRIC model incorrectly estimates the true cost of the investment. The second point, and a very different one, is that even if a compensation scheme were to estimate the cost of an investment correctly, it would not provide socially optimal incentives for investment and innovation because it limits returns.

A useful cost model must account for sunk and irreversible investments, for expected changes in the prices of capital goods (and other inputs) and demand, and for unexpected changes in prices and demand. These are not very controversial points. Economists for incumbents and entrants agree with these principles. And the FCC implemented these principles in its pricing standards. The paper, however, would lead one to conclude that it is impossible to account for these factors within any 
framework, yet that private unregulated firms can make optimal investment decisions, and therefore a better solution would be just to deregulate them. But to make these private investment decisions, firms must account for the risks in some way. As a result, simply asserting that the FCC framework cannot account for these costs must be wrong. The framework can account for such costs, and the order specifically states that they should be taken into account.

The FCC's order stated explicitly that sunk costs, declining costs, and competitive entry may increase the depreciation costs and the cost of capital. Properly designed depreciation schedules should be able to account for the expected changes in asset values over time. Essentially there may be three ways to correct for the problems noted by this paper-in the depreciation schedules, in the cost of capital estimates, or in the fill factors. The combination of adjustments in these three variables should be able to account for the three criticisms of the TELRIC model put forward in the paper.

These adjustments contradict the statement that "TSLRIC assumes that all capital invested now will be used over the entire economic life of the new investment and that prices for the capital goods or the service being offered will not decrease over time." Both expected changes and a risk premium for unexpected changes in prices should be factored into a correctly implemented TELRIC (or TSLRIC) cost study. As a result, the criticisms of the FCC model are not valid because the TELRIC concept does incorporate the important considerations pointed out in this paper.

The next stage of the debate between entrants and incumbents is most assuredly the fight in state regulatory proceedings to determine prices for unbundled elements and the FCC's further notice about cost models. These proceedings should address the magnitude of the effects of the sunk investment, competitive risk, and declining capital goods prices. The magniture of the effects will depend on empirical estimates of the amount of sunk costs compared with total costs. This paper explicitly estimates only the markup for the sunk cost portion of total costs. This is a completely appropriate first step. But it is important to reiterate that the estimates presented here do not take the necessary second step of determining the ratio of sunk costs to total fixed costs for telecommunications.

A second area of debate in the regulatory arena will be the expected 
trend of input prices. Although this paper uses the significant decline in input prices for switches as an example, submissions to the FCC from incumbent local exchange carriers have claimed that input prices will actually increase over time. For example, the forward-looking cost studies and price cap productivity studies submitted by the incumbent carriers claim that loop prices are going up, not down, because of the need to bury cable rather than using poles, the increased cost of digging trenches, and so forth. If input prices are expected to rise, then the points made about the risk of changing prices, while still valid, lead to opposite conclusions about the level of prices.

It is also important to assess correctly the expected decrease in the value of assets due to the entry of competitive facilities, because resale and use of unbundled elements will not necessarily cause sunk investments to decline in value. In addition, it is important to assess the salvage value of a sunk asset-can it be moved elsewhere? If not, is it still suitable for use in the same place, but expected to garner lower revenue? In these cases, the risk is not 100 percent of the value of an asset, but rather the fraction that is exposed to competition.

In addition, the degree of uncertainty about the changes in these variables is clearly important to any investment decision and should be factored into the cost model. The paper is correct to point out that options clearly have value precisely because of uncertainty, but the paper is incorrect to assert that TELRIC model cannot incorporate such uncertainty.

Finally, there is the important debate about how to stimulate further investment and innovation in the network. The paper likens the costplus-a-reasonable-profit standard to allowing returns for a pharmaceutical company only on successful drugs at a regulated rate. Other interpretations of the rules and how they should be applied may be more pro-innovation. For example, a single product in a portfolio of risky investments should be allowed to garner a significant return (just like successful drugs or hit records) given the expected return of any individual project. Such a policy would be difficult to implement, but it is extremely important that the rules not be implemented in such a way as to take away any of the upside for firms that introduce successful innovations.

A second idea with respect to innovation would be to "freeze" the network in place now and implement unbundling rules for truly new 
innovations only after a reasonable period of time has elapsed. In this way, incumbents would have the incentive to provide enhanced services and to increase their investment. This alternative raises significant questions about the definitions of new services and whether the old services are still available, but it may provide some incentives for innovations while addressing some of the monopoly concerns.

Overall, although my comment is quite defensive of the FCC, I do want to say that the issues pointed out by Professor Hausman in the second section of the paper were very useful to the staff of the FCC as we wrote the Local Competition Order. In addition, I think that the framework for the quantification of the benfits of new services will be a very important tool for regulators dealing with regulatory restrictions on new services.

\section{Commentators' References}

$\rightarrow$ Berry, Steven, James A. Levinsohn, and Ariel Pakes. 1995. “Automobile Prices in Market Equilibrium." Econometrica 63 (July): 841-90.

Deaton, Angus, and J. Muellbauer. 1980. Economics and Consumer Behavior. Cambridge University Press.

Hausman, Jerry A. 1996. "Valuation of New Goods under Perfect and Imperfect Competition." In The Economics of New Goods, edited by Timothy S. Bresnahan and Robert J. Gordon. University of Chicago Press.

$\rightarrow$ Maskin, Eric, and Jean Tirole. 1988a. "A Theory of Dynamic Oligopoly: I: Overview and Quantity Competition with Large Fixed Costs.' Econometrica 56 (May): 549-69.

$\longrightarrow \rightarrow$ 1988b. "A Theory of Dynamic Oligopoly: II: Price Competition, Kinked Demand Curve, and Edgeworth Cycles." Econometrica 56 (May): 571-99.

$\rightarrow$ Pakes, Ariel, James A. Levinsohn, and Steven Berry. 1993. "Applications and Limitations of Some Recent Advances in Empirical Industrial Organizations: Price Indexes and the Analysis of Environmental Change.' American Economic Review, Papers and Proceedings 83 (May): 241-46.

$\rightarrow$ Pakes, Ariel, and Paul McGuire. 1994. "Computing Markov-Perfect Nash Equilibria: Numerical Implications of a Dynamic Differentiated Product Model."' RAND Journal of Economics 25 (Winter): 555-89. 